\title{
Illusions of Liveness: \\ Producer as Composer
}

\author{
Sam Logan
}

An exegesis submitted to Massey University and Victoria University of Wellington in partial fulfilment of the requirements for the degree of Master of Musical Arts In Composition

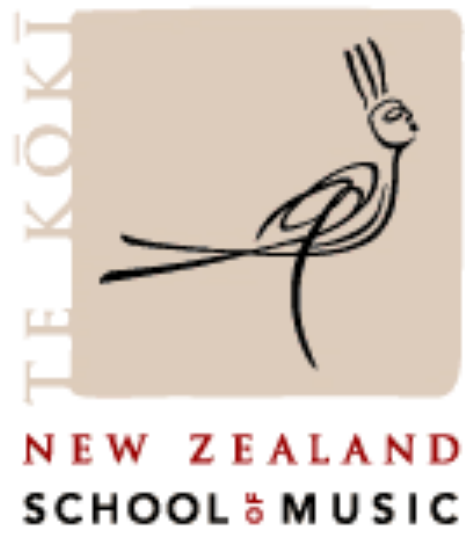




\section{Contents}

Introduction

I) Producer as Composer

II) The Producer-Composer as Cinematic Narrator

III) Modern Composition \& Production Tools

V) Conclusions

50

Bibliography

52

Glossary of Terms

55 


\section{Track Listing}

$\begin{array}{ll}\text { I } & \text { Tuna in the Brine } \\ 2 & \text { Flute VST Demo } \\ 3 & \text { Drums VST Demo } \\ 4 & \text { Choir VST Demo } \\ 5 & \text { 'Rite of Spring' (VST Instruments) } \\ 6 & \text { I) Garden of Earthly Delights } \\ 7 & \text { II) Chorale } \\ 8 & \text { II) Dizzy Night } \\ 9 & \text { IV) Vibrations } \\ 10 & \text { I Garden of Earthly Delights: (Early Unhumanized Version) }\end{array}$


Illusions of Liveness:

Producer as Composer

Sam Logan

Supervisor: Professor John Psathas

Secondary Supervisor: Dr David Cosper

\begin{abstract}
The practise of creating music for the recorded medium has been a fluid and constantly changing enterprise since its inception. Emergences of new studio technologies over the last fifty years have spurred new cultures, philosophies and approaches to music production and composition, ultimately seeing a merging of the once disparate roles of producer and composer.

It is this contemporary, technology-informed new role of producer-composer that brings with it discussion - for much of which there is no general consensus - over issues pertaining to perceived liveness, the producer-composer's control over the resulting sound, and most contentiously the use of music technology itself: its transparency and its legitimacy as substitutions for real instruments.

These are all fluid and complex issues and this paper does not attempt to provide answers for, nor take a definitive stance on them other than in the sharing of opinions formed from my own experiences in applying production as composition to the creative aspect of this project. In this paper I seek to share some of the current discussion regarding production-as-composition, in light of my own compositional experiment, which strives to create a simulation of real-performance via almost entirely artificial means within an idealised, hyper-musical sonic environment. By bringing together real musicians and virtual instruments within a recorded track and edited via music production technology, the experiment aimed to produce an illusion of liveness.
\end{abstract}




\section{Introduction}

This is the accompanying exegesis to an experiment in music production and composition. In combining the disciplines of studio-production, composition and orchestration, the objective of this project was the creation of a suite of four recordings that, to the unknowing listener, convincingly suggests that real musical performances were captured with real human musicians. The means used in striving for such a sound were however almost entirely artificial, with most 'performances' fashioned using standard studio production tools: Digital Audio Workstation (DAW) and Virtual Studio Technology instruments (VSTs). 1

The motivation for undertaking such a seemingly 'deceptive' project was multipronged. First there is the experimental goal to strive towards an all-encompassing creative control over my own output; to have a command over even the most infinitesimal nuance of timbre and gesture, as well as on a more macro level, to have control over the sound of the sonic space in which the music sits. This aspiration is ultimately realised in the production of a definitive master-copy recording: an audio document of an ideal performance entirely constructed by the composer and 'unadulterated' by anyone else's input. This lies in contrast to the written score, which even after final publication inevitably becomes a collaborative effort when subject to conductor and performer interpretation upon each live performance.

Second is a recognition of the limitations of sonic possibilities in live acoustic space compared with the myriad of possibilities in artificial recorded sonic space when using dimensions like artificial instrumental balance and treatment of the stereo-field as a sonic stage2: a dimension of compositional expression not possible in acoustic space.

\footnotetext{
${ }^{1}$ The DAW and VST comprise the foundation of the production tools used in this project. The DAW is the computer programme environment in which audio is composed, arranged and ultimately produced. The VST is a virtual instrument that uses real recorded samples of articulations of a corresponding instrument and can be controlled to essentially mimic the performance of any instrument. These will be explained further in chapter III

${ }^{2}$ Mark Katz coins the term 'Sonic Stage' to describe audio's stereo-field in which 'sounds occupy and move through space in a recording'. Mark Katz, Capturing Sound: How Technology Has Changed Music. University of California Press, 2010, p. 42.
} 
The final stimulus is a desire to hone the craft of Instrumental Performance Simulation ${ }^{3}$, for I can see many practical applications for this skill set. The Digital Audio Workstation and Virtual Studio Technology Instruments not only prove useful compositional tools, but also allow the composer to produce realistic sounding audio that can serve as creative and pedagogical aids, or indistinguishable simulations of formidable musical projects that otherwise would be too ambitious and costly too tackle if performed live. ${ }^{4}$

\section{A Note On Musical Style In My Suite}

This is quite a departure from my usual compositional style for academic work; indeed this whole project is quite a daunting departure from anything I have done musically.

My wish was to merge the orchestration skills I had learned from my university music education, with some more instinctive popular and rock sensibilities I have ingrained from playing in bands for many years, to form my attempt at the well trodden, but rarely successful, orchestra-meets-rock genre.

Although I have heard many attempts at what I deemed to be a poor marrying of the two ensembles, what I believe to be one of the more successful is John Psathas' 'Little Bushman: Live in concert with the NZSO'5. This concert demonstrates not only extreme attentiveness to the balance between orchestral and rock instrumentation, but a deep sensitivity to the style and character of each piece resulting in a sense of unity; one powerful organic sonic force is heard, rather than two insoluble ensembles playing at the same time.

'Little Bushman: Live with the NZSO' as concept was, in part, both an inspiration and model for this project. In my suite I merge orchestral and rock instrumentations and draw from many stylistic elements to produce music showing influences of chorale, Impressionism, classical, latin, rock, funk and Motown across the four tracks.

\section{Liveness}

At this point I wish to elucidate on the type of liveness my project seeks to simulate. Philip Auslander describes the notion of liveness as being

\footnotetext{
${ }^{3}$ Instrumental Performance Simulation is a term I am using to describe the producer-composer practise of fabricating what sounds to be a real performance by a human instrumentalist, via production technology. This concept falls under the wider umbrella of Jean Baudrillard's theory of 'Simulacra and Simulation' in the blending of 'reality' and representation, where there is no clear indication of where the former stops and the latter begins. Jean Baudrillard, Simulacra and Simulation. University of Michigan Press, 1995.

${ }^{4}$ Again, let it be known that in no way am I endorsing VST instruments over the real instrumental performances they are designed to simulate. Given the opportunity and resources I would hands-down, always choose real musicians over VST instruments for recording scenarios.

${ }^{5}$ Little Bushman, 'Karanga', in Little Bushman: Live in concert with the NZSO, 2010.
} 
...actually an effect of mediatization, not the other way around. It was the development of recording technologies that made it possible to perceive existing representations as 'live' performance, for that category has meaning only in relation to an opposing possibility. ${ }^{6}$

Liveness becomes a problematic and blurry concept as soon as a performance is recorded by music technology and subsequently reproduced via loudspeakers. Even in 'live' orchestral recordings it is commonplace to read on the back of the CD something to the effect of 'NZSO recorded over three days at the Michael Fowler Centre', essentially implying the splicing together of several takes has occurred; a technological intervention which most definitely cancels out the performative authenticity of true liveness.

In my project it would be extremely ambitious to attempt to recreate a true (or even spliced) live concert to the same effect as playing back a recorded performance of opera in an opera house, or jazz trio in a club, and this was not my intent. I aimed to construct a plausibly real performance by using both recorded musicians and VST instruments within an aurally enhanced, stereo-field or sonic stage to create an almost hyper-musical experience for the listener. A useful analogy that might help describe the type of hyper-musical liveness I endeavor to construct is the experience of watching a televised sports game on a High-Definition screen. ${ }^{7}$ The multitude of camera angles: wide-angle shots to view the game as a whole, and close-ups revealing the player's emotions, plus the largerthan-life resolution of High-Definition make this a hyper-real, heightened sensory experience. Ironically, the viewer is given a simulated experience that is sensorially more vivid and in a sense perhaps more 'real' than actually being there in the stadium viewing with the naked eye.

In much the same way, the tools of studio production in recorded music allow for control over hyper-musical elements such as perceived proximity, perceived left or right and instrumental balance, to the effect where musical 'close-ups' and wide angles can be achieved within the sonic stage giving a heightened sense of experiencing a piece of music than attending a live concert would otherwise permit. ${ }^{8}$ When listening back on stereo speakers or headphones, the listener is given admission into this sonic stage which, at the producercomposer's control, can give an aural experience akin to that of the mobile-listener during a live concert, walking about the auditorium, from left to right, even across either side of the stage and right through the orchestra so as to hear the many balances of instruments from different angles and proximities. The intimacy headphones give to the listener makes for an aurally immersive and help accentuate a hyper-real experience for the listener.

\footnotetext{
${ }^{6}$ Philip Auslander. Liveness. London: Routledge, 1999, p. 51.

${ }^{7}$ Whether the broadcast is 'live' or a replay is irrelevant to the effect here.

${ }^{8}$ Albin Zak, The Poetics of Rock: Cutting Tracks, Making Records. London, University of California Press 2001 pp. $146-148$
} 
As a means of grappling with this elusive concept, I have come to understand the experience of hearing music can be categorized into five tiers of perceivable liveness. ${ }^{9}$

I) True Live Performance: As experienced by a live audience in a concert hall or other performance venue.

II) Live capture: An ensemble or soloist recorded live and reproduced as an identical aural replica.

III) Studio Edited Recording: An idealized performance constructed from separately recorded instrumental parts. This can range from as simple as a Glen Gould 'splicing'10 to as complex as a multitude of individually recorded notes on variety of different instruments. At this level the producer has the control to maintain or reveal the illusion of liveness by either making transparent the technology or breaking the fourth wall. 11

IV) Artificial VST Production: A Simulated or Illusory live performance constructed from VST instruments, which in turn are libraries of micro-samples of a real instrument, recorded as played by a real musician.

V) Instrument Modeling: A synthetic representation of real instruments designed via electronic synthesizer. Nothing live exists in this category other than the real-time live playback via loudspeakers. (This tier, though useful to note as a reference in the context of the liveness 'spectrum', does not apply to this project).

\footnotetext{
${ }^{9}$ Whereas Auslander does discuss the relationship between 'liveness' and 'mediatization' (as he coins it) as being one of 'dependence and imbrication rather than opposition' (Auslander, Liveness, p. 53), he doesn't express specifically a particular categorization of levels of liveness. My postulation of tiered degrees of liveness is a derivation from both writings of Auslander and Paul Sanden. Sanden's ideas describe a virtual liveness imagined suggesting the listener subconsciously attaches a perceived performance to even the most mediatized and abstracted recordings.

Paul Sanden. 'Liveness in Modern Music: Musicians, Technology, and the Perception of Performance'. New York: Routledge. 2013 pp. 113-120

${ }^{10}$ Glen Gould describes his practise of recording several takes of a piece and splicing the first half of ones performance with the latter half of another.

Glenn Gould. 'The Prospects of Recording'. High Fidelity. Vol. 16, no. 4, April 1966 pp. 46-63.

${ }^{11}$ Here I am borrowing the theatre or cinematic term 'breaking the fourth wall' to describe the breaking of the illusion of liveness by revealing the studio technologies used in the production, and thus the artificiality of a track, often for effect and common in popular music. Examples of such technology revealing events include the entire track stuttering or playing in reverse, or the sampling of unrelated and atmospherically incongruous material; essentially any event that is physically impossible in the live acoustic world. Elizabeth S. Bell, Theories of Performance, Los Angeles: Sage. 2008, p. 203.
} 
My project incorporates elements from tiers III and particularly IV, yet strives to create an illusion for the listener that a hyper-musical III or even II is occurring. I wished to construct an ideal performance whereby I have had the luxury of control over every parameter, yet uphold an illusion that this is a performance by human musicians. ${ }^{12}$

\section{Exegesis Overview}

The following chapters scratch the surface of what is an extensive and multifaceted topic. Here in 'lllusions of Liveness' I have examined some of the theories, methodologies, and ongoing discussions pertaining to the role of the producer-composer and, have demonstrated how these approaches have informed my own composition. Chapter one will explain the merging of producer and composer into one influential artistic role and examine ideas concerning the studio as an instrument, the sonic stage and the transparency of technology. Chapter two recognises this new artistic role of producer-composer and that the function it serves draws many parallels with the metaphorical cinematic narrator as described in film theory. Chapter three sheds light on the standard modern production and composition tools used in the creation of my works, while chapter four details my suite of four pieces, explaining the compositional process and techniques applied in the effort to create an 'illusion of liveness'.

12 In that way, this project could be thought of as a next-generation version of Glen Gould's 'Splendid Splice' whereby I can choose the best performance down to the micro-managed individual note level by using spliced recordings and VST instruments. Gould. 'The Prospects of Recording.' pp. 46-63. 


\section{The Producer as Composer}

In the modern practise of music production, the once quite separate roles of producer, engineer, session-musician and composer are fast becoming blurred. With a radical shift in paradigm and philosophy having taken place over the last half-century of recorded music, skills from each discipline can often be found cross-pollinating within the individual now simply called 'producer'.13

Once responsible primarily for technical duties regarding the capture of a performance, and subsequent determining how best to exhibit that performance within the context of a greater piece of music, the title of producer can now denote an allencompassing artistic role. Decisions pertaining to the more traditional producer's role, including instrument selection, sound balance, mixing, and mastering are now found in combination with skills usually found only in the composer, such as the devising of melodic, rhythmic and harmonic material. As literacy in each of two disciplines converges, the apex of creative autonomy comes in the form of artists producing their own work. 14 The producercomposer now wields unprecedented creative control over every nuance heard in a recording.

Several inextricably linked factors can be traced to the rise of the producer and include: Advances in music technology and its increasing sophistication, the surpassing of recorded music's presence over live performance with the advent of hi-fi home audio, and trending tastes and audio expectations of audiences are all influential. 15 More recent still, and outside the realm of professional music production, a rise in the amateur or up-and-coming producer-composer can be attributed to the increasing prevalence, affordability and ease of use of music technology in the software form of digital audio workstations coupled with a growth in the technological and computer literacy of musicians.

In this chapter I will look into the fluid and interchangeable roles of producer and composer, examining the evolution of the disciplines into their current hybrid state. I will

\footnotetext{
${ }^{13}$ Comprehensive histories of early developments in recording technologies and practise can be found in:

Virgil Moorefield, Producer as Composer, Cambridge, Massachusetts: MIT, 2010 pp 1- 15

Albin Zak, The Poetics of Rock: Cutting Tracks, Making Records, University of California Press 1997 pp 1-17.

${ }^{14}$ Some of the earliest instances of composers to also qualify as producers can be traced to $1950 \mathrm{~s}$ pioneers of electronic and music concrete styles (Vladimir Ussachevsky and Pierre Schaefer for example) whilst more recently, Hip Hop as a genre has helped make common the conflation of the two roles in popular music. The duo Outkast for example become one of the first acts to secure a number one charting album and be credited with production as well as song-writing roles (Moorefield, Producer as Composer, pp xiv - xviii).

${ }^{15}$ Moorefield, Producer as Composer, pp xiii.
} 
discuss the rise of the producer from a solely technical role to one encompassing creative influence and how this new role helped to define the sound of radical new genres in the 1950s and 1960s, with special regard to Phil Spector and George Martin. This chapter will also examine the concept of the studio as an instrument controlling the sonic stage, and how this new creative control of the producer-composer affects the compositional process and consequently, the music itself. Finally I will explore whether use of the studio and its technology informed tools can allow the composer to achieve autonomy over their own works which was one of the goals in the creation of my own suite.

\section{The Rise of the Producer}

A detailed history of the evolution of early production technology falls outside the ambit of this exegesis but it is important to note that if not for some of the astounding technological advances in the first half of the twentieth century, the producers discussed in this chapter would not have had the careers and influence that they did. ${ }^{16}$ Perhaps the most important technological breakthrough was the advent of magnetic tape (introduced to the United States in 1941) and its use in creating multi-track recordings. This allowed the producer's role to develop from largely technical and concerned with capturing an artist's live performance in the best way, to an artistic one with scope to create idealised and often 'impossible' performances from several recorded takes, overdubbing the same performer multiple times. ${ }^{17}$

Throughout the 1940s and '50s these new recorded 'impossible-performances'; products of the studio, were reinforced and accepted in the public consciousness by increasing popularity and affordability of home hi-fi audio systems, to the point where music heard as a recording was more common than music heard as live performance. This scenario of studio advancements coupled with democratised home audio that helped set the ball rolling for producers to have unprecedented influence in new music.

\section{Technician to 'Auteur'}

\footnotetext{
${ }^{16}$ For more comprehensive history of early production technology see Moorefield, Producer as Composer, Chapter 1.

${ }^{17}$ A well-known early example of this is Les Paul and Mary Ford's recording of 'How High The Moon' comprising a total of 12 guitar and 12 vocal takes of Ford's vocals overdubbed, creates an impeccable yet somewhat unnatural degree of blending.

Les Paul and Mary Ford, 'How High The Moon', Capitol, 1951.
} 
Since 1950s the producer's role transformed from the purely technical to the creative and artistic, but as Virgil Moorefield also points out, 'recording's metaphor has shifted from one of the "illusion of reality" (mimetic space) to the "reality of illusion" (a virtual world in which everything is possible).' 18 Indeed, the initial aim of recording was to bring the luxuriant and exclusive experience of the concert hall to the living room: a simulation of liveness for home listeners. This was the case for all genres of recorded music with one early form of orchestrated pop music called fine music, noted especially designed for its in-home simulation of the elite concert experience.

The home listener to a recording of fine music was granted a virtual access to the acoustic regime of the concert hall, an acoustic regime which already had embedded in it highly ordered codes of privilege and exclusion. ${ }^{19}$ (Doyle, 2004)

However, it wasn't long before an influential marriage of new technological innovations and an emerging radical new sound called rock'n'roll in the 1950s would pave the way for a new era of recording, ultimately challenging the way audiences heard and perceived records, and transforming the ideals and approach producers employed in creating them.

1950s rock'n'roll records comparatively lacked the rhythmic and harmonic sophistication that contemporaneous records of jazz, classical and even Fine Music possessed, however, new production techniques such as tape editing, overdubbing and special effects like tape echo made rock'n'roll music's point of interest its unique aural atmosphere: an entirely artificial, studio created sound. ${ }^{20}$ This concept would be developed greatly in the following decade.

Enter Phil Spector and George Martin. Though these two producers' musical outputs were very different, both of their production efforts showed little interest in continuing the pursuit of musical realism, and instead pioneered sound aesthetics that would be acoustically impossible in the physical world, and could only occur within the artificial sonic boundaries of recordings themselves. In other words, what Martin and Spector strove for was an 'appearance of a reality which could not actually exist - a pseudo-reality, created in synthetic space...their interest lay not in replicating the natural world, but rather transforming it into something else...21.

This marks the beginning of interest in a new sonic dimension of compositional expression. Treating the stereo-field as a sonic stage within which physical boundaries found

\footnotetext{
${ }^{18}$ Moorefield, Producer as Composer, pp xiii.

${ }^{19}$ Peter Doyle. 'From “My Blue Heaven" to "Race with the Devil”, . 2004, p. 34.

${ }^{20}$ Moorefield, Producer as Composer, p. xiv.

${ }^{21}$ Moorefield, Producer as Composer, p. xv.
} 
in the acoustic world do not apply and therefore could be altered for compositional effect was the beginning of treating the studio itself as an instrument. ${ }^{22}$

\section{Studio as instrument: Using the sonic stage as a hyper-musical dimension}

Mark Katz describes the sonic stage, the stereo-field of audio - as differentiated from the live acoustic world - as the domain in which 'sounds occupy and move through a space in a recording. 23 The producer-composer's exploiting of the sonic stage can be particularly noticeable to the listener when using headphones due to the experience of stereophony at such an intimate proximity, and the effect of stereo imaging and panning is particularly pronounced.

An example is the George Martin/Beatles work 'Strawberry Fields Forever'. ${ }^{24}$ The track begins with an organ heard in the left ear followed by vocals appearing seemingly, in the middle of the listener's to the effect of the music passing through you from left to right.25 Similarly, Jimi Hendrix's 'Cross-town Traffic'26 sports an extreme, full left to right pan of the entire sound field in the sonic stage, mimicking the busy passing of cars. Such production techniques can be seen as evidence of hyper-musical dimensions of compositional expression previously untapped in traditional approaches to recording, and impossible in real acoustic space.

The Martin produced Beatles 'Tomorrow Never Knows'27 is arguably the most significant early departure from the traditional recording paradigm of imitating sonic conventions of live performance, as the track delved into previously unexplored use of the studio as an instrument. As a means of controlling and sculpting the sonic stage of audio as a dimension of compositional expression, not only did Martin exploit the effects of sounds' perceived location (as controlled via stereo-panning), but explored the effect of juxtaposing sounds from differing sonic spaces within the one song. ${ }^{28}$

A number of distinct sonic strata can be observed in the song. The 'Hypnotic, riveting ostinato of Ringo Starr's drums, coupled with the bass, unchanging throughout the entire song, a well-selected assortment of tape loops fed to the faders of a mixing console,

\footnotetext{
${ }^{22}$ In his lecture during 'New music New York' Brian Eno explains how his experience with studioenvironment approach to composition presents an unprecedented level of creative control when compared with traditional instrumental/vocal composing approach. Brian Eno, 'Pro Session: The Studio as Compositional Tool', Down Beat 50, 1983. pp. 65-67.

${ }^{23}$ Katz, Capturing Sound, p. 42.

${ }^{24}$ The Beatles, 'Strawberry Fields Forever', on Penny Lane, Parlophone, 1967.

${ }^{25}$ Katz, Capturing Sound, p. 42.

${ }^{26}$ Jimi Hendrix, 'Cross Town Traffic', on Electric Lady Land, Reprise Records, 1968

${ }^{27}$ The Beatles, 'Tomorrow Never Knows', on Revolver, Parlophone, 1966.

${ }^{28}$ Moorefield, Producer as Composer, p. 30 Differing sonic spaces refers to the acoustically impossible idea of a sound with acoustic qualities from one location being heard simultaneously with a sound sporting an acoustic quality from another location.
} 
and John Lennon's vocal. ${ }^{29}$ Each of these instrumental elements exhibits wildly differing sonic properties. The drum's ride cymbal is drenched in reverberation while the snare drum of the same instrument possesses a 'low-level reverb tail, which gives the listener the feeling of being located next to something located in a very large reverberant space'. 30 Heard simultaneously are a variety of reversed guitar solos, along with the vocals, both which appear in close proximity.

It is clear to the analytical listener that what is being heard is an acoustic impossibility with each sonic stratum clearly having come from a different acoustic space. However, as Brian Eno says of recordings '....almost any arbitrary collision of events listened to enough times comes to seem very meaningful.'3। I believe here Eno is describing the power of suggestion recordings can have over the listener, who, can accept a recording comprised of even the most disparate sonic strata so long as the recording can bring about unity in some way. In the case of 'Tomorrow Never Knows' the sonic strata, though sonically different, align in terms of harmony, rhythm, and all fall under a song structure allowing the recording to be heard and understood, as a unified performance.

This use of the studio as a means of bringing together differing sounds is a good example of a new way of thinking about the studio as compositional instrument. This way of thinking would prove an influential model for many future recordings and allows for an unprecedented level of creative control. ${ }^{32}$

\section{The producer's creative control and 'autonomy' over work:}

If George Martin began a trend of new reaching creative control in his work with the Beatles using the comparatively primitive studio equipment of the 1960s, today the contemporary producer-composer now has access to a seemingly unlimited number of production tools at his or her disposal, allowing for almost limitless creative control. ${ }^{33} \mathrm{n}$ ways this might seem to draw parallels with the Beethovenian notion of the heroic composer; lionizing the romantic ideals of complete control over the orchestra and his own sound; a force of nature to be reckoned with. ${ }^{34}$

In my project I am indeed striving for an all-encompassing creative control over the sound of the audio having micro-managed my VST instrument performances down to the most infinitesimal subtleties of gesture and articulation. With regard to the live musicians to whom I must surrender my control to their interpretation, I explicitly gave detailed

\footnotetext{
${ }^{29}$ Moorefield, Producer as Composer, p. 30.

${ }^{30}$ Moorefield, Producer as Composer, p. 30.

${ }^{31}$ Eno, 'Pro Session: The Studio as Compositional Tool', pp. 65-67.

${ }^{32}$ Moorefield, Producer as Composer, p. 32.

${ }^{33}$ Zak, The Poetics of Rock, p. 107-111.

${ }^{34}$ Scott Burnham, Beethoven Hero, New Jersey: Princeton University Press, 1995.
} 
performance instructions and recorded multiple takes of an excerpt in an effort to capture a desirable performance.

Despite the pursuit of absolute creative control I can appreciate the condemning of this practise as inherently 'unmusical' or sterile with the presence of true human performance being as far possibly removed from the recording equation, especially with regard to having a VST replace the human musician altogether.

This is a highly contentious issue and has had me in somewhat of a moral dilemma throughout the project. At the time of writing this exegesis I spend much of my days in a music conservatory socialising with, writing for, and hearing, musicians who practise meticulously every subtle articulation and gesture. Who am I to actively engage in the practise of illusory performance that - in theory - makes redundant live instrumentalists in recording scenarios?

The inevitable progress of technology does bring about irreversible changes in the culture of recorded music scenarios, however I don't believe this dystopian future for instrumentalists is one of them. Having interviewed several audio-engineers I am now of the opinion that studio professionals, although partial to the functionality of VST instruments, believe the characteristic of human performance is a trait inimitable by any simulation technology, and given the resources and budget, will almost always opt for live musicians over their VST counterparts when possible. ${ }^{35}$ Though simple block-chord padding of VST strings, for example, is acceptable in sustained, unanimated passages or where the music takes a backseat role to visuals (such as in film or T.V.), any instance where the music is an important focal point, and especially a melodic one, will require real musicians. ${ }^{36}$ Whereas using the right reverbs and other studio techniques can produce convincing results for padded VST string ensembles, the audio engineers I have spoken with are yet to find a VST instrument they are confident in using for a solo melodic role.

A common practise for when budgets do not permit a full human ensemble is a blending of the two. In most cases the higher or melodic parts are given to real musicians and lower padded parts are given to VST instruments. This is an approach taken in my project.

A significant aspect of the desire for creative control is the idea of pure, unadulterated compositional autonomy i.e. the striving for independence of the composer's

\footnotetext{
${ }^{35}$ These consensuses were drawn from conversations with audio engineers John Neil, Mike Gibson, and Lee Prebble.

Mike Gibson, Interview at Munki Studios, $24^{\text {th }}$ November, 2013.

John Neil, Interview at Park Road Post Productions, 15 October 2013.

Lee Prebble, Interview at Surgery Studios, 23 May 2013.

${ }^{36}$ Consensuses drawn from conversations with John Neil, Mike Gibson, and Lee Prebble.
} 
musical ideas from the agencies that are required to bring them into sonic existence. Eno similarly describes the predicament that occurs when composing in the traditional instrumental/vocal style in terms of a series of 'transmission loss'. Such 'transmission intervals in a classical sequence' he includes as tainting the composer's original vision are: the language of notation (often inadequate in expressing the composer's ideas), the 'intransigent' musicians performing the piece and finally a conductor whose interpretation of the piece might be wildly different to the composer's. ${ }^{37}$ Conversely, he claims the studio-based producer-composer experiences no transmission loss due to the producer-composer's empirical approach to working with sound, much in the same way a painter works directly with materials, continually adding and manipulating ideas as they come. ${ }^{38}$

Eno's claims describe the compositional process in its idealised form with minimal agency, but when arguing that there is no transmission loss in studio-based composing he leaves out the original transmission loss: that from the composer's aural imagination to the technology used to bring sound into the world. Imagine a sound in your head that does not yet exist in the sonic world, then envisage trying to reproduce this sound without the agency of performers (human or virtual) tainting the sound of your originally imagined idea. This is quite impossible with the technology of today. At their highest aspiration, the use of VSTs and other studio technologies as I am using in this project, are an attempted step in the direction of gaining as much control possible over performance by replacing the human performer with a virtual one, that seeks to translate every definable performance characteristic into parameters that can be modified by the producer-composer's to his or her liking. ${ }^{39}$

This project is certainly a step in the direction of compositional autonomy, however some degree of transmission loss through human performer or even the most customizable of VST instruments is inevitable. The host of technicians and musicians needed to make the VSTs I am working with all put a particular taint on each sound: the type of microphone used, the player's unique instrument and performance, and the user-interface of the virtual instrument are all predetermined. A VST, regardless of how customizable will always be inextricably linked to several other creators meaning true autonomy of composition only exists within the composer's mind. A composer's musical output is and will always be, even if indirectly, a collaborative effort.

\footnotetext{
${ }^{37}$ Eno, 'Pro Session: The Studio as Compositional Tool', pp. 65-67.

${ }^{38}$ Eno, 'Pro Session: The Studio as Compositional Tool', pp. 65-67.

${ }^{39}$ In contemporary VST technology it is possible to 'dial in' most if not all 'human' performance elements of articulation, dynamics, rubato and accelerando etc. for a near complete control of a performance.
} 


\section{II \\ The Producer-Composer as Cinematic Narrator}

The newly emerged role of producer-composer has evolved rapidly, and continues to evolve faster than much of the literature and theory describing it. We can observe that this technologically informed, multi-disciplinary role has allowed for unprecedented creative influence and control over audio, however there seems to be no general consensus when describing this role's musical function and purpose from a theoretical standpoint. Despite this lack of consensus, one particular thread that crops up frequently is the parallel drawn with film.

Moorefield proposes the idea of the 'producer as auteur' 40 with regard to both George Martin and Phil Spector, who he describes to be 'in effect attaining a status akin to that of a film director. The mise-en-scène which has been the domain of the record producer widened in scope, as did his artistic role.'4l The musics' mise-en-scene can here refer to Katz' sonic stage and the musical and hyper-musical events arranged and sculpted within it. 42 Perhaps more usefully we can draw parallels in the role of producer-composer with the more metaphorical cinematic narrator as described in film theory.

The producer-composer as cinematic narrator can be thought of as the symbolic behind-the-scenes influence, narrating and illustrating a piece of music via control over musical and hyper-musical sonic elements within the sonic stage of the audio, much in the same way the cinematic narrator narrates all elements of the story in film with minimal agency.

In this chapter, using the orchestral-rock song 'Tuna in the Brine'43 by Silverchair as a case-study, I aim to show how, that in much the same way as the cinematic narrator is responsible for creating the illusion of one seamlessly unfolding narrative in a fictional world in film, via a variety of film techniques, the producer-composer similarly controls musical and hyper-musical features inside the sonic stage with the intent of producing a particular sound world in which a musical narrative takes place, in the form of a simulated live performance.

\footnotetext{
${ }^{40}$ Moorefield, Producer as Composer, p. xv.

${ }^{41}$ Moorefield, Producer as Composer, p. xv.

${ }^{42}$ Hyper-musical aspects include stereo-panning, and adjusting the perceived proximity of instruments and their balance between one another.

${ }^{43}$ Silverchair, 'Tuna in the Brine', in Diorama, Atlantic (Refer to track 1 of accompanying CD).
} 


\section{Defining the Cinematic Narrator}

Whether literature, theatre, film or music, all narrative mediums can create immersive experiences for the audience and convey a strong sense of an engaging 'storyline'. The presence however, of a distinguished and identifiable storyteller for each will significantly differ from medium to medium. Whereas theatre and literature might exhibit a character internal or external to the plot and through whose eyes the narrative is depicted, in film, as in music, the source of a narrator can often be significantly more elusive. In fact film study discourse evidenced much debate as to whether the narrator, as we know this role, can be said to exist. As Robert Burgoyne explains, 'because film is a visual rather than a verbal medium, and does not imply a literal speaker or hearer, some theorists argue that the need to designate a narratorial source for the representation of the fictional world is obviated: the events of the fictional world simply "tell themselves" ,. 44

Following this literature-modeled definition I tend to agree, however in music we are dealing here with an entirely different form of narration; one that does not involve the presence of a designated illocutionary source, but rather a type that minimizes the agency and presence of the narrator in a style described in Burgoyne's article as impersonal cinematic narration. ${ }^{45}$ This implies a cinematic storytelling style that is devoid of any identifiable agency personifying the narrator such as voice-overs or narration from any character within the story.

It is vital to explain in detail just what exactly this impersonal cinematic narrator entails in order to differentiate from other narrative forms and shed light on this style of narration and its correspondence to recorded music. From several author's explanations of the cinematic narrator, it seems to be a fairly fluid concept.

Burgoyne defines the cinematic narration theory as two-pronged, explaining that it 'both creates or constructs the fictional world while at the same time referring to it as if it had an autonomous existence, as if it preexisted the illocutionary act', and then further elaborates that it 'creates a universe that, once established, cannot be revoked, for the discourse provides the very basis of the fictional world, forming the material building blocks of the fictional universe'. ${ }^{46} \mathrm{He}$ adds that 'In creating the fictional world, the Impersonal Narrator produces a type of discourse that is read as the facts of the "real world" of the fictional universe (and that) the impersonal narrator's lack of human personality allows the viewer to imagine that he or she is confronting the fictional universe directly, putting aside any reflection on the form of the narrative discourse. ${ }^{37}$

\footnotetext{
${ }^{44}$ Robert Burgoyne. The Cinematic Narrator: The Logic and Pragmatics of Impersonal Narration. Journal of Film and Video (ARCHIVE): Spring 1990, p. 4.

${ }^{45}$ Burgoyne. The Cinematic Narrator. p. 4.

${ }^{46}$ Burgoyne. The Cinematic Narrator. p. 7.

${ }^{47}$ Burgoyne. The Cinematic Narrator. p. 7.
} 
Seymour Chatman explains his cinematic narrator as more of a visual guide to the events unfolding onscreen stating 'the convention is that the particular rectangle of visible material constitutes a "favored view," a selection by the implied author, which the cinematic narrator is delegated to present. That selection entails a certain distance and angle, certain lighting conditions, and so on-those that maximize the story's impact.'48

Katherine Thompson-Jones provides ideas of the cinematic narrator that lend themselves to application in popular music production. As well as describing cinematic narration as 'an implicit visual narrator of the story from the inside, or from a fictional point of view', she speaks in terms of a film's 'tone'49. Thompson-Jones assigns the cinematic narrator responsibility for that tone or quality resulting from decisions made over the film's technical and creative constituent parts of 'lighting, cinematography, mise en scène, and editing of both the image and sound tracks.' 50

In synthesizing these definitions I understand the cinematic narrator to be a type of experiential lens, with minimal agency, for the viewer, tinted by the resultant sum of those aforementioned constituent cinematic parts (lighting, cinematography, mise en scène, and editing of both the image and sound) which describes the physical 'realities', laws and boundaries governing the fictional world created. In much the same way, the producercomposer is also concerned with both technical and creative studio decisions, which, in music's case pertain to compositional elements of harmony, timbre, rhythm and tempo, and more technical and aesthetic elements of reverb, compression, mixing and mastering in order to illustrate and 'narrate' the intended 'fictional' sonic world. By closely looking into the recording of 'Tuna in the Brine', giving particular attention to aspects of production I endeavor to show the presence of the 'Cinematic Narrator' and how this parallels the producer-composer's role.

\section{'Tuna in the Brine' - (CD Track I)}

My choice of recorded track 'Tuna in the Brine' admittedly seems an all too easy choice for drawing comparisons with film given that on the most superficial level it does indeed display obviously 'cinematic' signifying elements of full symphonic orchestration and rich Neo-Riemannian ${ }^{51}$ style harmony - elements that lend themselves to film music. But I

\footnotetext{
${ }^{48}$ Seymour Chatman, Coming to Terms: The Rhetoric of Narrative in Fiction and Film (Ithaca, NY: Cornell U.P., 1990), p. 156.

${ }^{49}$ Katherine Thompson-Jones. The Literary Origins of the Cinematic Narrator. Oxford. Journal of Aesthetics, Vol. 47, No. 1, January 2007. pp. 78 - 80

${ }^{50}$ Thompson-Jones The Literary Origins of the Cinematic Narrator. 2007 p. 78

${ }^{51}$ Here I reference Neo-Riemannian theory (for lack of a better adjective), to describe the style of harmony that is based on relationships between triadic chords with a high emphasis on voice leading, and without necessary reference to a tonic. The theory has been applied especially to film and pop music.

Michael Norris, 'Neo-Riemannian Theory \& triadic post-tonality in film scores \& 80s pop' Lecture. Materials of $20^{\text {th }} / 21^{\text {st }}$ Century Music Lecture, NZSM, 2 May 2011.
} 
see this track as strictly a pop song, albeit a more structurally and sonically complex one than the average radio hit and with a much more immersive quality, such that this song can be experienced with the same sense of absorbing narrativity found in film. In only a small number of measures the 'building blocks of the fictional universe' are laid down by the producers. 'Tuna in the Brine' opens with a pronounced and deeply indrawn breath from the vocalist before immediately beginning the first verse. Accompanying this tenor voice is a simply strummed steel-string acoustic guitar that rocks between $C$ and $A b$ chords and together with voice outlines $\mathrm{C}$ mixolydian harmony. Beneath this, murky sul ponticello, tremolo strings perform a murmuring chromatic gesture before commencing an eerie stringharmonics glissando up to a cadence marked with a timpani hit. As the first verse continues more orchestral instruments emerge with the addition of harp, woodwind and brass steadily revealing the full orchestra. With a final upward octatonic scalar gesture in strings, the orchestral, band (drums, bass and guitar) and vocal parts converge to reveal the full magnitude of the ensemble: a timbrally rich completed rock-cum-orchestral aural picture that moves at a steady walking-pace tempo in 6/8 time.

Within just 30 seconds a sound world has been established that a listener might describe as mysterious, dream-like, ethereal; but what is it about the construction, at the essential barebones level of the track, that is responsible for this kind of experience? Without trying to resort to overly convenient analogies to film, I do see at least partial parallels between technical aspects of both mediums. The first can be observed on the spectral level where the music's timbre and harmony corresponds to the narrative content of film. As outlined above in the brief analysis of the opening of 'Tuna in the Brine', the timbrel and harmonic content certainly holds much of the song's emotional affect, in much the same way as film does via its characters and the scenarios in which they are placed.

The second is that of the spatial level between audio mix and film's cinematography. Whereas in cinematography the combined technical aspects of lighting, lens selection, composition and exposure, are used to control the aesthetics of a captured moving image in film, so too does the use of audio mix in relation to the way a track's raw musical material is exposed, expressed and 'coloured'. I use the term 'mix' as a blanket term to include all technical aesthetic processes that together form the overall tone-colour or hue of the raw recorded sound and include use of reverb, equalization, stereo-spatialization and of course the sound balance between instruments. 


\section{The Sonic Stage}

In 'Tuna in the Brine's' opening thirty seconds it can be ascertained that the song's 'cinematography' can be thought of as a composite of three distinct layers or sonic strata that comprise the musical mix. Although these musical layers all fluidly weave in and out of the track's focal centre stage, as a general rule they are arranged in the following way:

At closest proximity lies the voice as the focal point; this sits atop the rockensemble of drums, bass and guitar; and finally furthest at the bottom of the mix sits the orchestra. Just as in a film shot, these three layers respectively correspond to first a film's subject, well lit and focused in the foreground, followed by the immediate surrounding miseen-scéne, followed by the scene's backdrop. In this way the voice as the focal point of the song, might be assimilated to the protagonist character of a film with the volume balance and stereo spatializing placing the singer at the forefront of the aural picture throughout the duration of 'Tuna in the Brine'. This sense of proximity can largely be attributed to the producers' decisions regarding microphone placement to the singer.

The article 'In “My Blue Heaven to 'Race with the Devil'”, Peter Doyle describes Les Paul's then revolutionary production techniques used in recording voice as evidenced in his million selling (and now jazz standard) 'How High the Moon'. Doyle explains that prior to Les Paul, it was common practise that all vocal recordings, even those of crooners, were made with the microphone placed at arms length, a method that 'located the listener in comradely proximity to the voice'. 52 In 'How High The Moon' however, Les Paul has his singer and wife Mary Ford sing 'lipstick on the mike', which allowed for an unprecedented sense of intimacy and even a 'familial or erotic closeness' which Doyle describes as having a 'smoldering rather than explosive affect'. ${ }^{53}$ I believe a similarly 'smoldering' and highly intimate closeness is achieved in 'Tuna in the Brine' using a 'lipstick on the mike' technique as evidenced by the first-heard indrawn breath and continually breathy vocals.

Although nowadays it is standard practise for all pop songs to record lead vocals 'close miked' for that desirable sense of intimacy between singer and listener, 'Tuna in the Brine' takes this notion one step further by capturing in isolation and thus emphasizing, the in-breath of the vocalist immediately prior to the music starting at the beginning of the track. As an effect utilized by a producer, this could be understood as a musical equivalent to the cinematic device of a close up shot where all emotion and vulnerabilities can be shown in an amplified form.

\footnotetext{
${ }^{52}$ Doyle, Peter. 'From 'My Blue Heaven' to 'Race with the Devil: Echo, Reverb and (Dis)ordered Space in Early Popular Music Recording'. Popular Music. Vol. 23, no. 1. Cambridge University Press, 2004, p 39.

${ }^{53}$ Doyle. From 'In 'My Blue Heaven' to 'Race with the Devil'’. 2004, p 39.
} 


\section{On Reverb}

While a very important colouristic aspect of production and applied broadly to almost every individual instrument in a recording, I think it necessary to bring up the effect of reverb as it applies specifically to the voice. For contemporary listeners this overlooked effect is virtually taken for granted due to its ubiquitous presence in all popular music production. This however begs the question: What necessitates reverb? Intuitively I would answer this with the simple reasoning that reverb produces that rather aesthetically pleasant sense of space upon an otherwise unappealingly dry and dimensionless sound. However as Doyle explains, 'the relationship between reverberation and the human voice in particular has a complex semiotic history, which far predates the invention of sound recording. ${ }^{54}$ Though highly unlikely that producers consciously think beyond aesthetic effect, Doyle offers an explanation for what they are signifying on a subconscious level through the use of reverb and states that 'atavistically, that the phenomenon suggests that the world is animist: the non-human possesses human characteristics, it 'talks'. Echo suggests at once the possibility of a deep, extended reciprocity between the self and the world, just as it indicates a total imprisonment in selfhood'55. If we acknowledge reverb to be something that occurs naturally in the world, and which is always present, then its use by producers in popular music gives credence to the producer sharing the traits of the cinematic narrator who, "both creates or constructs the fictional world while at the same time referring to it as if it had an autonomous existence' as previously stated by Burgoyne. 'Tuna in the Brine' uses quite a liberal amount of reverb on voice and throughout the rest of the mix and this is what gives the fictional universe of 'Tuna in the Brine' its spatial setting. The physical 'realities', laws and boundaries governing this fictional world are ones that suggest a great deal of space.

\section{Transparency of Technology}

The second stratum in the mix comprises the drums, bass and guitars of the band Silverchair, which are essentially the meat and potatoes of the song.

At this level the role of the producer becomes more complex, now taking on an arranger's role. I believe there is also much more awareness of the balance between both second and third strata which together provide the 'building blocks of the fictional universe' or sonic world described here in 'Tuna in the Brine'. Significant implications for production are evident at this level, for the producers are now working with both forces of orchestral and rock ensembles, and each is contextualised by very different understandings of recording and listening.

\footnotetext{
${ }^{54}$ Doyle. 'From 'My Blue Heaven' to 'Race with the Devil', 2004, p 32.

${ }^{55}$ Doyle. 'From 'My Blue Heaven' to 'Race with the Devil', 2004, p 32.
} 
Whereas when listening to any recording of orchestral recorded music, it is by convention expected that what is heard is simply the natural capturing of an acoustic space (a real concert hall or room), in which some time ago a real performance was experienced that took place in real-time. Conversely, in any modern pop music recording it is by convention understood that the sound we are hearing is a completely artificial (and often acoustically impossible) construction yet at the sub-conscious instinctive level, we do in fact hear it as a live performance. Philip Auslander articulates this idea by stating that 'Only a few rock records foreground the artifice of their studio construction; most are made to sound like performances that could have taken place, even if they really didn't (and couldn't). ${ }^{56}$

As is often the case when producing a pop or rock ensemble in the popular music idiom, the task at hand is to construct a simulated live performance, although via very much artificial means, essentially creating the illusion of liveness. On this, Simon Frith says "I listen to records in the full knowledge that what I hear is something that never existed, that never could exist, as a 'performance,' something happening, in a single time and space; nevertheless, it is happening, in a single time and space: it is thus a performance and $\mathrm{I}$ hear it as one. ${ }^{57}$ The illusion of liveness requires a suspension of disbelief in the listener and in the case of "Tuna In the Brine" it is the cohesive sense of unfolding narrative that suspends listener disbelief. Without it the illusion would be broken and reveal the artificial mechanics behind the production, tearing down the 'building blocks of the fictional universe'.

Of course, in other popular musical genres such as hip-hop and electronica music it is accepted or even expected that the 'fourth wall' be broken as the technology behind the recording is exposed and even made a focal point. The rock-pop genre however requires a more subtle treatment. As Olivier Julien explains 'The work of many rock bands and musicians owes as much to "the technology" they use to realize their ideas' as to the ideas they use to 'divert' technology. ${ }^{58}$ Specifically in regard to the progressive pop-rock 'Tuna In the Brine', success in narrating stems from the producer's ability to mask the technology used and seamlessly stitch together the separate musical parts and sections (scenes) to create one cohesive sense of narrative.

\section{Recording}

While surely received differently from listener to listener, in 'Tuna in the Brine' at least part of the intended musical image the producers are trying to allude to is that of the band playing live on stage with a symphonic orchestra behind them. As evidenced in the

\footnotetext{
${ }^{56}$ Philip Auslander. Liveness. London: Routledge, 1999 p. 64.

${ }^{57}$ Simon Frith. Performing Rites: On the Value of Popular Music, Cambridge: Harvard University Press, 1996.

${ }^{58}$ Olivier Julien. 'The Diverting of Musical Technology by Rock Musicians: The Example of Double Tracking'. Popular Music. Vol. 18, no.1. Cambridge University Press, 1999, p. 357.
} 
short film Across the Night: The Creation of Diorama, this couldn't be further from the reality of the recording sessions. ${ }^{59}$

In this rather brief and quick paced documentary we see behind the scenes footage with songwriter, producer and arranger discussing their ideas and approaches to the album, interspersed with shots of individual instruments or instrument sections in session. Initially we see just solo drums being laid down, followed by bass and then several guitar tracks separately recorded in a textbook example of multi-track recording. ${ }^{60}$ As the documentary goes on we see the band and their manager in a phone call to orchestrator and arranger Van Dyke Parks who upon hearing the band's demos, has come to some decisions regarding instrumentation and calls for a small orchestral ensemble including 'strings, a trombone and a couple of flutes, an oboe, 2 clarinets and a bassoon... oh and I love three French horns'. 61

Though perhaps a little bigger than a chamber orchestra, this sized ensemble does not in the slightest reflect the full symphonic scale heard in the 'Tuna in the Brine'. The ensuing scenes show Parks in rehearsal and recording sessions with the small brass and string instrumental ensembles and then hearing the playback with the band in the control room. Producer David Bottrell exhibits the desire to attain the 'big' sound by remarking on a section featuring brass 'can we double that?'62

The resultant symphonic sound, although artificially constructed and exhibiting a tightness unattainable in live performance, is presented convincingly enough to fool any lay listener and successfully create and sustain an illusion of liveness. Here the producers have made virtually transparent the agency of technology and overdubbing techniques involved, helping establish and sustain the fictional sonic world, much in the way the cinematic narrator does in film.

\section{Orchestra and Rock instrumentation}

The remaining third and lowest stratum in 'Tuna in the Brine's' audio mix is the orchestral sonic layer. The production decision to include Western Classical music's most traditional ensemble in a pop-rock context is somewhat contentious given the many failed exemplars in the past, prompting many to claim the pairing is 'kitsch' and that it waters down each respective tradition. Well received or not, producers continue to involve orchestral instruments in pop tracks and I regard 'Tuna in the Brine' as one of the more successful examples of this due to its tasteful and colourful orchestration, used to complement the song with colour and texture rather than provide sheer power and overpower the band.

\footnotetext{
${ }^{59}$ Robert Hambling. Across the Night - The Creation of Diorama. New South Wales, Australia: Atlantic/WEA, 2002.

${ }^{60}$ Julien. 'The Diverting of Musical Technology by Rock Musicians, 1999, pp. 357-365.

${ }^{61}$ Hambling, Robert. Across the Night - The Creation of Diorama. 2002.

${ }^{62}$ Hambling, Robert. Across the Night - The Creation of Diorama. 2002.
} 
Producers who add orchestration to pop songs do so in order to add a heightened sense of sonority, depth and colour to a fictional sonic world that is otherwise restricted by the limited palate of bass, drums and guitar. Perhaps it is due to its close association with film, or richly diverse and colorful timbre, but either way there is no denying the potent, image-evoking quality that the orchestral sound has on the imagination of the listener. To reiterate once more the early, recorded form of orchestrated popular music, known as 'Fine music', Peter Doyle sheds light on the phenomena of music possessing these vividly 'pictorial' qualities in the full version of the quote:

The home listener to a recording of fine music was granted a virtual access to the acoustic regime of the concert hall, an acoustic regime which already had embedded in it highly ordered codes of privilege and exclusion. Apart from these extrinsic political territorialisations, other intrinsic, prior musical spatialities also existed, best typified by the steadily increasing 'pictoriality' in Western orchestral music. In a development which roughly corresponded to the rise of landscape painting, eighteenth-century European composers such as Vivaldi, Handel and Haydn used musical means to denote events (and sites) in nature - the trilling of piccolos and flutes to represent birds, crescendos to denote the storm and so on. ${ }^{63}$

I am convinced that this strong sense of 'pictoriality' is present in 'Tuna in the Brine'; I certainly feel the rich orchestration adds a depth to the song, which would have an entirely different narrative quality without. I believe that the roles of narration share many similar attributes across both mediums of film and recorded music and can be evidenced by the presence of the cinematic narrator model. This definition provides an explanation for narration that is devoid of any illocutionary storyteller, which is the style that naturally exists in both film and recorded popular music as constructed by the producer-composer. Successful cinematic narration lies in a producer's ability to minimize the narrative agency by making transparent the studio technology that would otherwise reveal the artificiality of the recording and break the illusion of the fictional sonic world. Close analysis of 'Tuna in the Brine' reveals much about this style of narration, which is a fine example of successful cinematic narration in music by a producer-composer.

\footnotetext{
${ }^{63}$ Doyle. 'From 'My Blue Heaven' to 'Race with the Devil'. 2004, p 34.
} 


\section{III \\ Modern Composition \& Production Tools}

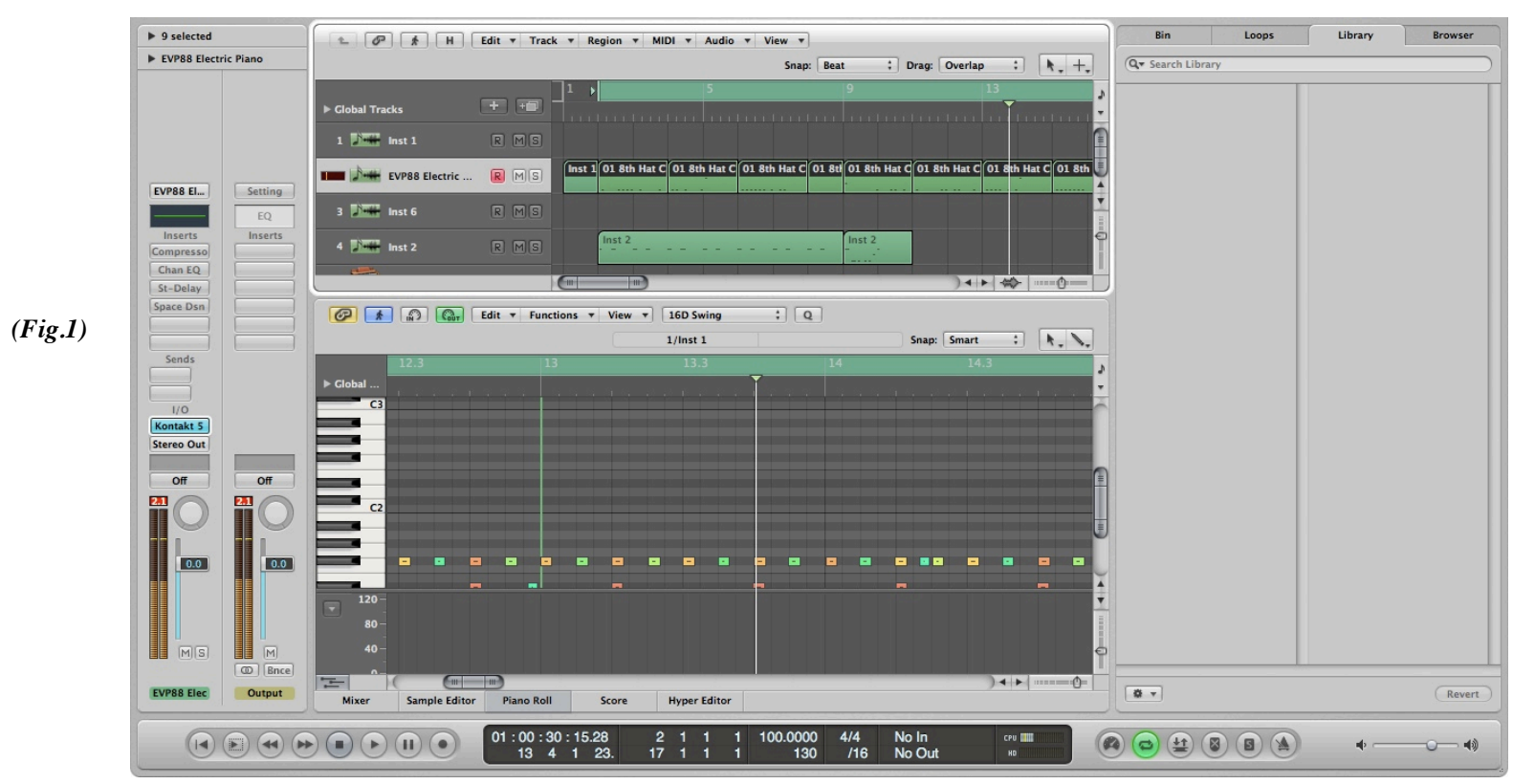

Screenshot of the popular Digital Audio Workstation Logic Pro ${ }^{\circledR}$ displaying both arrange window (top centre) and MIDI sequencing window (bottom centre). (Fig.1)

Digital production tools have made marked leaps in their sophistication and capabilities in recent years. Like many newly introduced or emerging technologies, there is not yet a general consensus on the virtue of their use, especially with regard to composition. In this chapter I will shed light on the production tools used in the creation of my suite, demonstrating their operation and the techniques employed in striving for the desired illusion of liveness. I will discuss how these tools can function as compositional aids and sketchpads for ideas and creativity, or as hindrances to orchestration pedagogy. I will also put forth potential practical applications of instrumental performance simulation, the skill that utilizes these tools. All tools used are computer applications and, with the exception of the final mixing and mastering process, all production, composition, arrangement and premixing was completed by myself on an entry level Apple MacBook ${ }^{\circledR}$ Laptop. $^{64}$

\footnotetext{
${ }^{64}$ My computing power, comprising a mere $2.26 \mathrm{GHz}$ Intel Duo Core Processor and $4 \mathrm{~GB}$ of RAM, is hardly deemed fast by today's standards and further emphasizes that this kind of production work can be achieved without expensive studio hardware, which was not the case up until very recently.
} 


\section{Regarding the Virtue of DAWs and VSTs}

Perhaps the most revolutionary achievement in music technology over the last 20 years is the collating of half a century's developments in analogue and digital studio equipment and making it available as a studio simulation in a Digital Audio Workstation. ${ }^{65}$ Many, if not most composers and all producers working today have at some point used one and there is no denying their usefulness in music production, especially in popular and film music genres. ${ }^{66}$ However I have come to appreciate two sides of an ongoing argument over the DAW's virtues especially with regard to the composing of orchestral and contemporary classical music.

New Zealand composer John Psathas has expressed enthusiasm for the DAW professing he will compose almost exclusively in Logic Pro ${ }^{\circledR 67}$, and then score the piece by hand.68 Psathas suggests that innately we are all (at least most of us) unoriginal and that it is in the reworking of, or even stumbling upon musical ideas by accident that true uniqueness comes about. Such accidents and the ease of rearranging and editing musical sections in environment DAW (through splicing, repeating, inverting, transposing, transferring to other instruments etc) makes the hearing back in real-time of quite drastic creative changes to your work a reality. This allows for the composer to easily hear a variety of options for the direction of a work during the composing process, and it is likely these options would have never have been realized outside of a DAW.

I too believe there is truly something to be said for being able to hear back in realtime, a simulation of the entire ensemble you are writing for. Through instrumental simulation using a DAW the composer is given the luxury of hearing a sneak preview of the finished product and this is something that can affect the composer-as-listener into experiencing a particular emotion. By being able to fully recreate this emotional affect in the composer-as-listener via orchestral simulation, I believe there could well be instances of spurred creativity that wouldn't otherwise exist when composing with only manuscript or at the piano. ${ }^{69}$

The argument against the DAW comes from the pedagogical standpoint that the DAW might become a crutch for the composer who will become reliant on it in order to compose, and who will gain an unrealistic expectation of orchestration and

\footnotetext{
${ }^{65}$ Chris Geddes, The Digital Revolution: The role of the Digital Audio Workstation in the cultural shift from analogue to digital audio, Otago: Otago University Press.

${ }^{66}$ John Neil, head of sound at Park Road Post Productions, a world-class film production facility, pointed out in an interview that ProTools ${ }^{\circledR}$ is the exclusive DAW used at the facility and is a standard part of every day work. John Neil, 15 October 2013.

${ }^{67}$ Logic Pro ${ }^{\circledR}$ is a Leading DAW, for Mac OS.

${ }^{68}$ These conversations have arisen during our frequent meetings as mentor and student.

${ }^{69}$ This is a firmly held conviction of mine, but it is difficult to demonstrate or measure.
} 
instrumentation. ${ }^{70}$ This I can see is a risk for when a composition is to have a life outside of the recorded medium and is to be played live. A very unrealistic ensemble 'tightness' is heard in the playback upon the initial input of notes, and sonic balance between instrumental sounds is by default, very unrealistic. For instance, when working with two virtual instruments of flute, playing in its lower register and a bassoon, also in its lower register, by default they will sound at the same volume in the DAW when played back together. A live performance would see the flute being entirely drowned out. On top of this, the budding composer inexperienced in orchestration and instrumentation can easily fall victim to writing outside instrumental range, as well as never coming to grips with the idiomatic eccentricities of the instruments the VST instrument is modelling. ${ }^{7 I}$ VST instruments in a DAW often use a keyboard as a physical and graphical means of operating the instrument. As a result, unrealistic performance expectations may arise if a producer-composer accustomed to operating every VST instrument with the physical fluency of a keyboard, writes with these expectations for a human performer of a non-keyboard instrument. 72

In my university education experience of instrumental-vocal composition, DAWs were available but predominantly used in tutoring for sonic arts and film courses. Time will tell if they ever make their way into the more traditional strand of composition.

\section{DAW Overview73}

In short the Digital Audio Workstation is a computer application in which a suite of tools provide everything needed to compose, record, arrange, mix and master music into a digital format of high audio quality. It was within this environment that my four tracks were completed, in essence from scratch.

Visually, DAWs are very intuitive. Horizontal divisions (tracks) provide a means of arranging sounds that correspond to an instrument's performance, which can be written, edited and played back in real-time. A DAW will often provide an easy access to a user's own library of virtual instruments and signal processing effects (plug-ins) which can be vast. The DAW functions as the environment in which the producer-composer controls everything within the sonic stage with virtually limitless creative scope.

\footnotetext{
${ }^{70}$ This argument against the DAW is one I have observed in a good number of educators who come from a more traditional musical background.

${ }^{71}$ I include myself as a victim; one instance was the DAW leading me to have unrealistic expectations of the trombone's glissando.

${ }^{72}$ A typical DAW is coupled with a MIDI keyboard through which one can 'perform' sounds of an instrument, imitated by the VST.

${ }^{73}$ For a comprehensive understanding of a leading Digital Audio Workstation, see The Logic Pro 9's user manual: documentation.apple.com/en/logicpro/usermanual/
} 


\section{Virtual Studio Technology Instruments ${ }^{74}$}

The concept and theoretical use of VSTs are simple. Essentially they are a means of utilizing a library of samples of an instrument, usually comprising that instrument's full range chromatically, and can be accessed in such a way that they can be played on a keyboard, and subsequently recorded within the DAW and edited. By arranging a series of input notes sequentially in the DAW a simulation of a real performance occurs upon hitting the play back control.

$$
* * *
$$

Here are graphical representations of selected VST instruments used in my suite along with a brief explanation of their operation and the techniques applied to make the technology transparent and strive for the illusion of liveness.

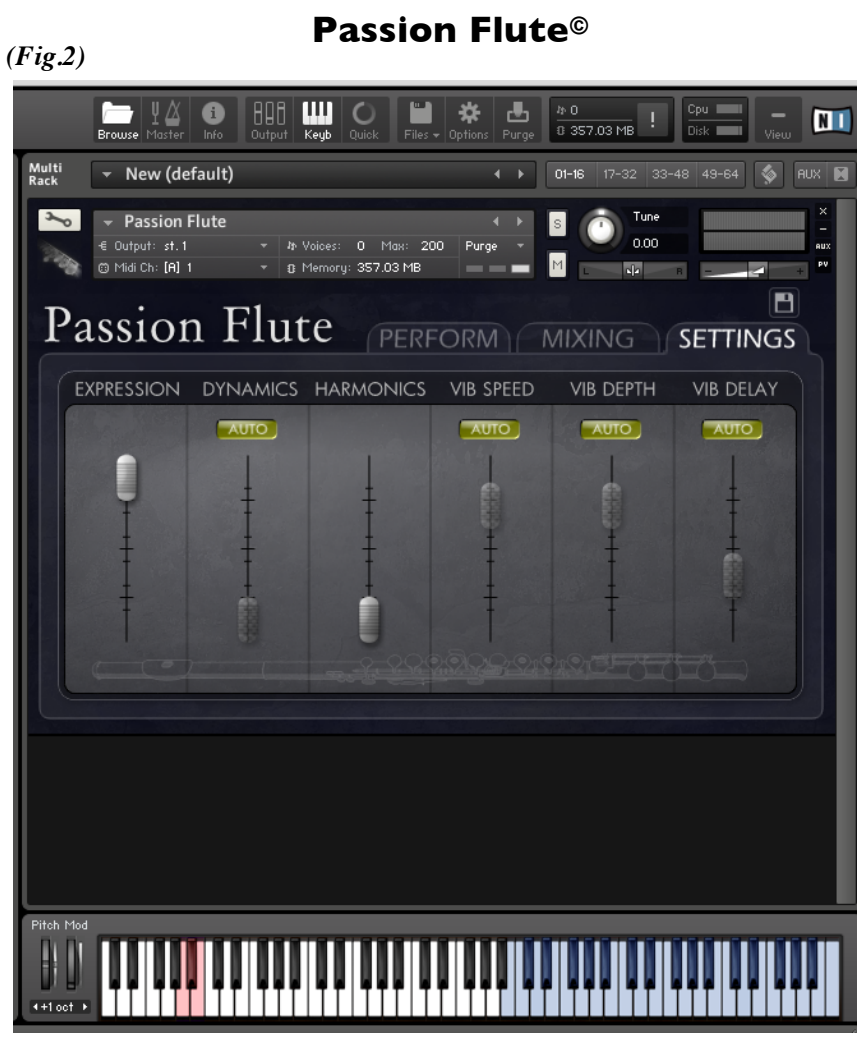

Passion Flute ${ }^{\odot}$ (fig.2) is a solo concert or jazz flute VST featuring the full range of the instrument (depicted by blue keys) and can be triggered to perform either staccato, legato or overblown articulations by activating the 'key switches' (depicted by the red keys.

In this and all VSTs, after inputting notes into the DAW the resulting 'performance' can be adjusted by changing performance parameters of dynamics, vibrato speed, vibrato depth and vibrato delay, giving a near

infinite number ways to articulate and shape a 'human' performance.

Controlled correctly, I believe this VST can come reasonably close to being indistinguishable from a live instrument partly because it includes subtleties such as key clicks and the performer's in-breath for extra 'simulated authenticity'. ${ }^{75}$

\footnotetext{
${ }^{74}$ For a more comprehensive understanding of VST instruments refer to Harman Audio, Steinberg Cubase VST: Audio Sequencer. Sound on Sound, 1996.

${ }^{75}$ Refer to CD track 2 for an original demonstration of the Passion Flute ${ }^{\odot}$ VST.
} 


\section{(Fig.3) Studio Drummer ${ }^{\odot}$}

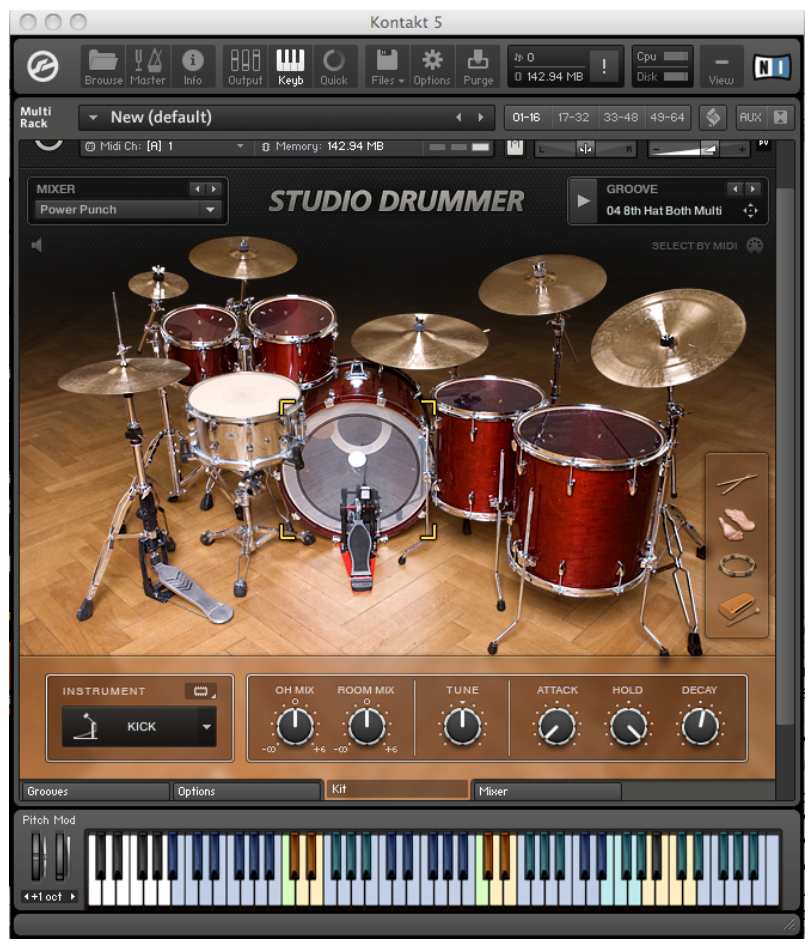

This is the VST instrument I have used most and features in tracks I, III and IV of my suite. It features a myriad of samples of articulations heard on a standard jazz or rock kit (Fig.3). Unlike the variety of complex articulations used in strings and voice, fixed, short attack of percussion instruments make them far more simpler to operate as VST replicas and I believe this instrument gave the most realistic sounding results in my compositions. Performance parameters that can be controlled include the velocity at which notes are hit, as well as the perceived tightness of the groove where notes are displaced from pure metronomic alignment or quantisation. ${ }^{76}$ In adjusting these, micro-imperfections are created in the performance and this is where the illusory 'human' element comes in. ${ }^{77}$

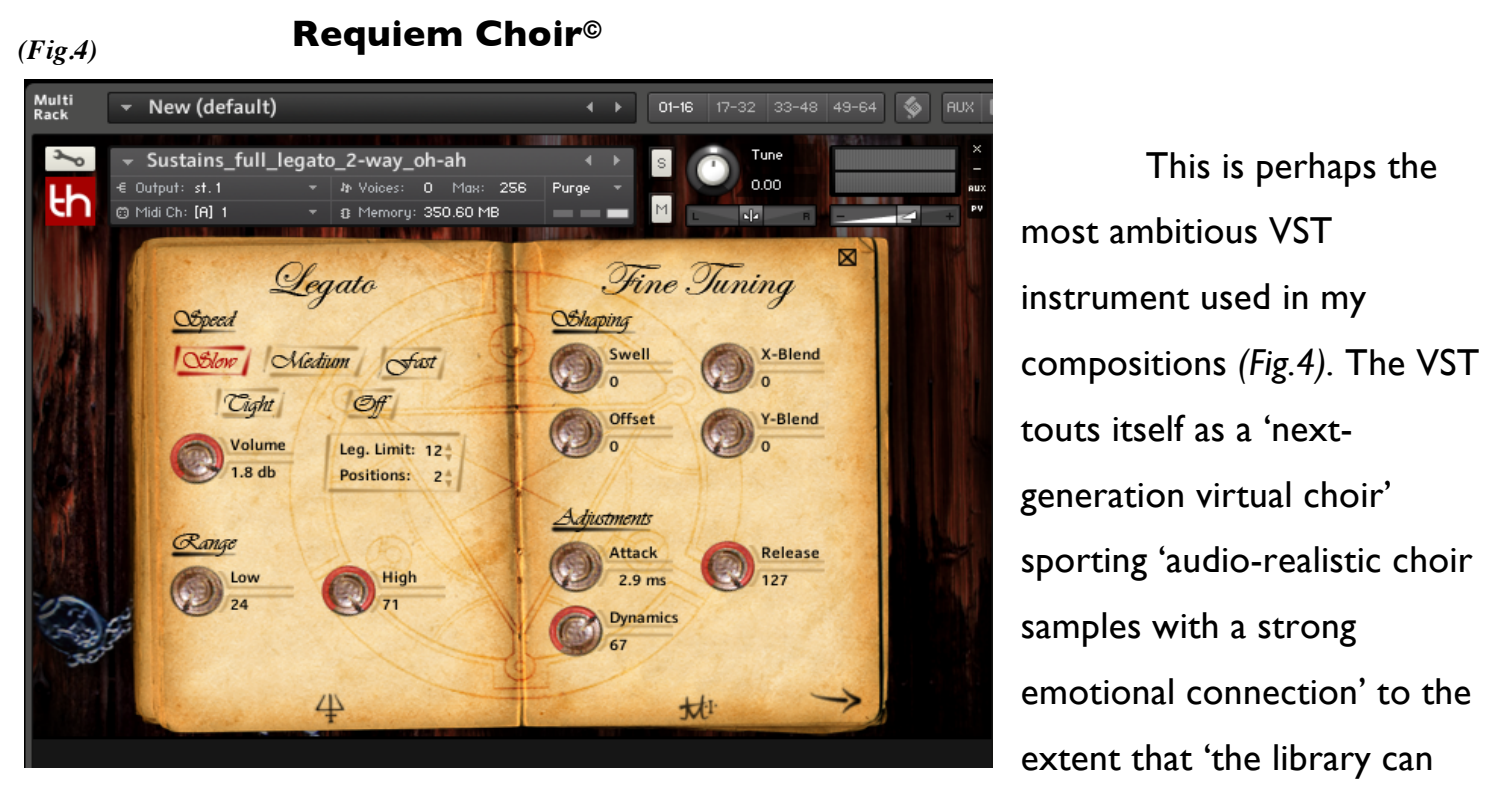

literally sound like a real choir'. ${ }^{78}$ Its samples cover a great range of conventional articulations, including short and sustained vowel sounds as well as a variety of whoops and

\footnotetext{
${ }^{76}$ Quantisation refers to the process of making MIDI input notes conform to a fixed set of discrete rhythmic values, often for a rhythmically metronomic effect.

${ }^{77}$ Refer to CD track 3 for an original demonstration of the drums VST.

${ }^{78}$ Mike Peaslee \& Troels Folmann, Tonehammer: Requiem Light (User Manual), Tonehammer 2010.
} 
screams, giving a broad palate of sounds to work with and the potential to create very lush harmonic textures.

Where as the samples individually are very realistic sounding, achieving the convincing effect of legato across a succession of notes is where difficulties arise and contribute to the breaking of the illusion of liveness. The performance parameters of the VST are all tailored towards creating a legato effect, and with the right adjustments of attack, swell and release a realistic legato voice sound is possible. ${ }^{79}$

\section{Culture of 'Realism'}

VST instruments and their sampler predecessors have been around for quite some time, yet only recently have companies developed libraries and sequencing technology that can be said to have reached a true instrumental realism when used in production. 80 Companies such as the Vienna Symphonic Library have released massively comprehensive libraries of recorded micro-samples flaunting every articulation performable on orchestral instruments, including extended techniques and even atmospheric, hyper-musical detail such as ambient room noise, chair noises and musicians breathing. ${ }^{81}$

Whereas early, more primitive sampler instruments sounded more like abstractions of the instrument they were imitating82, today's vastly improved technology has now spawned a new production culture pursuing instrumental realism. This has been made apparent to me by seeing a growing community of amateur and professional producercomposers sharing tutorials and works on YouTube in pursuit of VST instrumental realism. Uploaders are usually working out of a DAW and demonstrate techniques and tips for manipulating a sound library's default sound in attempt to create the illusion of a real instrument performance. 83

Interestingly this pursuit of realism can almost be thought of as an inversion of the philosophy and approach used in the Spector/Martin school of production. Whereas Phil Spector and George Martin deployed real instruments in unique ways to achieve new and acoustically 'impossible' sounds, this new technology driven culture of sample-library

\footnotetext{
${ }^{79}$ Refer to CD track 4 for an original demonstration of the Choir VST.

${ }^{80}$ One only need look at the last fifteen years to see marked improvements in realism. In flute samples for example the Yamaha PSR-170 keyboard's (1997) flute sound pales in comparison to Logic Pro's Xtra flute sample library (2004), which again doesn't compare to Orange Tree Sample's Passion Flute (2011).

${ }^{81}$ Refer to Vienna Symphonic Library's website for further information: www.vsl.co.at/en/65/71/84/1349.vsl accessed February 2013.

${ }^{82}$ Early sampler instruments include the likes of the Roland 808 drum machine and string and flute synths of the 1980s and 90s and although served the same rhythmic or timbrel function as the instruments they were imitating, they certainly weren't fooling anyone into thinking they were the real thing. The Roland 808 drum machine for instance is more of an electronic abstraction of the drum kit which sounds like anything but real drums, but serves the same beat-keeping function

${ }^{83}$ An example of such amateur tutorials sharing techniques for creating realism can be found in this video entitled 'Creating Realistic Strings (from MIDI )'.

http://www.youtube.com/watch?v=Ce989ZsUWuA; accessed February 2013.
} 
production strives for the reverse: the illusion of reality via entirely artificial means. Here technology is made as transparent as possible

\section{Real World Practical applications}

I believe the skill set involved in the creation of realistic instrument simulations via the aforementioned music technologies has great potential in real world scenarios. Upon browsing the websites of several VST production companies it is commonplace to hear musical 'demos' of their products showcasing their virtual instruments. One particularly ambitious venture a company undertook in 2009 was the commissioning of a skilled producer-composer to create a purely VST instrument edition of The Rite of Spring using only their library of VST instruments. ${ }^{84}$ It is clear that the technology used here is still considerably far from reaching a sound indistinguishable from the real thing, and the rapid scalar flourishes in particular sound very artificial. However, significant technological improvements have been made in the four years since this effort emerged, to the extent where indistinguishable simulations of the orchestral sound are perhaps only a few years away from the time of writing this exegesis. The skill set involved in this kind of work can be applied to the following real world scenarios.

\section{As a Pedagogical and Memory Aid}

At this time of writing I have been fortunate enough to receive a commission for a work of mine to be played by the NZSO's National Youth Orchestra, and I intend to produce a VST instrumental 'mock-up' of the new work, in conjunction with a score. In conversation with musicians from the ensemble, many have expressed strong enthusiasm for this idea of hearing in full a new, pre-premiered work (albeit in virtual form) before endeavoring to learn the piece.

I personally have experienced dreadful first rehearsals of my own works that I believe could have been avoided (or the severity of the dreadfulness reduced) had the musicians been given a VST instrument mock-up to use as a supplemental aid to the sheet music. The luxury of working in a DAW with 'read and write' 85 capabilities over every track means that not only can I create a MIDI mockup of the entire work, but I can also create MIDI mock ups of individual parts. When it comes to the reading sight reading of exceptionally tricky rhythms or notes high in the stratosphere of ledger-lines, I believe an

\footnotetext{
${ }^{84}$ Stravinsky, 'Rite of Spring' 2009, sequenced by Jay Bacal. Refer to CD track 5

Originally sourced from Vienna Symphonic Library website:

www.vsl.co.at/en/67/3920/4700.vsl\#; accessed February 2013.

${ }^{85}$ Read and write refers to the ability to hear back as well as edit musical input.
} 
aural guide for musicians would help reduce needlessly wasted minutes in precious rehearsal time. 86

\section{Work-Shopping Works in Progress}

I believe it very useful, also in the pedagogical sense, to be able to share a work in progress with others as part of a presentation or seminar in order to gain feedback and critique from a purely intuitive and direct perspective from listening to your work, rather than discussing the score of a piece yet to be performed. Throughout the course of this project I have shared the progress of my works with my creative supervisor. Because the excerpt of the piece being discussed can be played back in real-time and opinions given as the music is played, the feedback process can be much more efficient than with a score alone.

\section{Pitching an Idea}

Being able to express a musical idea to a non-musical person can be a very difficult feat without some means of showcasing the idea in aural form. Take for instance the scenario of the composer pitching his ideas to a film director or producer. It is in the interests of everyone involved that the musical idea is expressed in its best and most complete possible form. In the past ideas have been shared via piano reductions of a proposed score, but by simulating a full orchestral performance the director and composer have the advantage of hearing a simulation of the finished product. ${ }^{87}$

\footnotetext{
${ }^{86}$ These are general observations I have made from conversations with musicians from NZSM and NZSO National Youth Orchestras.

${ }^{87}$ John Neil, Interview, 15 October 2013.
} 


\section{IV \\ The Illusion of Liveness: The Suite}

The musical experience I intended to create in this suite was that of an ideal live performance. Using DAW and VST technologies I set out to create realistic sounding instrumental performances within the context of an enhanced, hyper-musical sonic stage.

This chapter details the creative process and technical measures taken in completing the suite, and how such measures strive to achieve the desired illusion of liveness. ${ }^{88}$ The tracks comprise some real, but mostly VST, instruments; recorded and sequenced respectively, then arranged within the DAW environment. The decisions concerning which instruments were to be performed with real musicians were informed by knowledge of the instruments I believe are yet to be realistically recreated in a VST form such as solo voice and strings, especially when performing passages with much movement and legato phrases.

It is well understood in the production world that while many VST instruments excel in simulating instruments very realistically, they fall short when it comes to others. Instruments that produce sounds of an 'inherent fixed envelope' 89 nature, as well as exhibiting a fixed playing action (such as harp, piano, percussion or anything else that is struck or plucked) lend themselves well to VST simulation. Conversely, instruments possessing a greater variability and expressivity in their attack, decay and articulation as well as having their own technical idiosyncrasies and eccentricities prove to be, by nature, more formidable to simulate. Specifically, I refer here to bowed string instruments.

\footnotetext{
${ }^{88}$ A means of gauging the success of this aim should be indicated by the first-time listener (who has no prior knowledge of the music's production background), giving a response indicating either suspicion or obliviousness to any artificiality regarding performance. To this end, I did not conduct a formal test, but more informally I have 'quizzed' an audio engineer and my supervisor on the 'realism' in my tracks and in most cases neither could identify with complete certainty, which instruments heard were real and which were VSTs. Interestingly, for track III the engineer guessed that the performance of some string runs were MIDI and the drums real. In fact the opposite was true.

If I were to take this experiment further, a formal test using a good sample size of thirty or more experienced musicians as subjects would be useful to gauge how truly convincing my tracks are in replicating performance. I would play the tracks and for each ask them to pick out the instruments they hear, and then whether the performance of them is real or MIDI sequencing.

${ }^{89}$ In audio engineering the 'envelope' refers to the curve joining the successive peaks of a sound wave. Musically, this instrument having one type of attack and decay which essentially remains the same throughout its range. A more detailed explanation of instrument sampling can be found in Ethan Winers 'Add Realism to Your Synthesized Sequences', Recording, November 1997.
} 
As I understand it, strings seem to be perhaps the most difficult instrument to imitate in a sampler, in ensembles but especially solo. ${ }^{90}$ Ultimately this informed my decision to use real instruments for all of my string parts, with the exception of all pizzicato and some sustained passages where I believed I could use VST instruments successfully. The ensemble I believed would give me enough just enough weight and range in colour to work with, yet not exceed my limited budget was a string octet.

\section{Recording Session: String Octet}

Comprising four violins, two violas and two cellos this ensemble provided my tracks with the majority of the string sounds heard in the suite including tremolo, glissandi, trill, arpeggio and scalar articulated passages. Having mostly completed the composing of the suite I produced a miniature score for string octet that consisted of sixteen excerpts, each ranging from 5 to 45 seconds in duration and providing a variety of articulations and instrument combinations within the ensemble.

Preparation for the recording session included liaising both with a technician and a viola player who was to lead the session. I met with each of them some weeks before the recording to plan out the session in order to make it run as smoothly as possible. This was vital given that a mere 90 minutes of recording time was available due to other performer's commitments. We arranged that the entire session was to be recorded live with the hope that in that time at least one useable take could be made for each of the excerpts. The viola player and I created a rehearsal sheet on which we noted the estimated time needed to run through each excerpt in order to get a useable performance. Along with deciding upon an appropriate order of the excerpts, this was an effort to avoid running over time and ultimately proved very helpful.

After a few last minute score alterations to help facilitate sight-reading and playability the recording session commenced with the eight musicians, one technician and myself coordinating the session. Although all musicians had received and rehearsed the music individually, they hadn't as an ensemble, and naively I assumed a tight performance would come after the first few run-throughs. This wasn't the case and I hadn't fully accounted for the rehearsal required during the recording session. My worries were compounded by the abrupt technical failure of the recording gear, where the recording computer required rebooting and a considerable amount of reconfiguration. Miraculously we

\footnotetext{
${ }^{90}$ This is merely an observation, but having scoured the Internet, at the time of writing this exegesis, I have yet to see the emergence of a truly convincing strings VST instrument. The large-orchestral sustained string sound VST sound is passable when used in slow moving passages and their heavy use in television dramas is testament to that fact. However when it comes to any other gesture or articulation with melodic movement, string VST instruments often struggle to retain their illusion of authentic performance, with cumbersome, inorganic and 'early-video-game-like' results.
} 
managed to use this down-time to rehearse the entire list of excerpts and by the time the recording gear was back up and running the ensemble was able to move swiftly through them all within the 90 minutes.

A conductor was not employed in the session and the ensemble played to a click track for time keeping. Tempo is of prime importance to this recording as the excerpts were melodic and rhythmic (rather than sustained chordal textures) and by ensuring the group kept strictly in time, this would allow me to relocate and edit the recordings within my DAW project knowing it would fit precisely into my yet unfinished piece.

The string octet recording session brings more interesting discussion to the table regarding my moral dilemma concerning real musicians and VST instruments. I am happy with the results of the recording, I believe that eight was the right number to give enough depth and grain, and both suits and blends into the track well. Having said that, the costliness both financially and in terms of stress was such that I do question whether I would chose real over VST strings in the future for a similar project. The cost of eight musicians for merely 90 minutes isn't cheap and for the same price I could purchase a considerable quality VST instrument that although may not give the same authenticity, with the right amount of fine tuning could certainly bring me close, and would unquestionably be less emotionally taxing. On top of this, whereas an audio recording is more or less set in stone once captured, the ability to edit any VST in a DAW is an unparalleled luxury.

Assuming VST technology continues to improve at the rate that it has over the last fifteen years, it won't be long before VSTs reach a level that is indistinguishable from a recorded real performance of any articulation. Coupled with the technology becoming ever more affordable, VST can only become a more tempting option for recording scenarios in the future.

\section{The Suite}

The four works all differ greatly from each other in terms of musical style and have all had a variety of different techniques applied to each in order for them all to obtain their own illusion of liveness. In this section I will give an overview of each piece with regard to compositional process within the DAW environment, the techniques applied in striving for realistic instrumental performance simulations, along with decisions from a producercomposer and cinematic narrator perspective pertaining to the shaping of the sonic stage. 


\section{I) Garden of Earthly Delights \\ CD Track 6 |4:27|}

\section{VST Instruments}

Passion Flute ${ }^{\odot}$

Percussion

Drums

Bass Guitar

Cuban Upright Piano

Baby Grand Piano

Strings (Pizzicato articulations only)

Requiem Choir ${ }^{\odot}$ ('Sweep’ Effects Only)

French Horns

Celeste

Harmonica

Synthesizer Bass

\section{Real Instruments}

Soprano Voice

Choir (Multi tracked Soprano Voice)

Strings (Arco runs and melodic material only)

[4 Violins, 2 Violas \& 2 Cellos]

Garden of Earthly Delights is a dramatic, percussion driven, cinematic styled piece of music featuring orchestral, rock and soprano voice instrumentation. Lyrically very abstract, the text depicts a young woman on the brink of insanity, hearing voices, and speaking in riddles before being plunged into a surreal euphoric state. With regard to narrative in the music, I wished to convey the sense of danger and excitement of a cinematic chase scene with unexpected twists, turns and stops, followed by a cathartic, arrival of new material that is huge, ethereal and psychedelic.

\section{Compositional Process}

I can say with complete confidence that had I been without a DAW, this piece could not have been composed. This piece is a good example of the DAW serving as a sketchpad for, and extension of my own creativity, and was the exclusive composition tool used to develop the work. Unlike the other three pieces in the suite, I had not set out any preexisting harmonic or melodic ideas nor a formal plan or structure for the piece before beginning work in the DAW. Garden of Earthly Delights in its most primordial form was nothing more than the combination of a vague idea of a mood that was tense and dramatic, 
and a two-bar rhythm I had taken from an unfinished piece. From here it was a matter of pure, unbridled gut-instinct aided by the DAW's live playback tool that allowed Garden of Earthly Delights to come into existence.

In composing this piece especially, the ability to hear back the progress I had made in real-time, helped tremendously to stimulate the compositional urge to 'uncover' what needed to come next in the piece by replicating that same 'momentum' the listener experiences when hearing a piece of (completed) music: the expectation that there is more to follow. For me the process was putting myself into a mental state in which during playback I heard not my own piece but rather an excerpt of an already finished piece of music. Essentially I was trying to listen as casually as I would any track in my personal music library, sometimes not even paying full attention. When the playback came to an abrupt halt where my progress terminated, it was my task to then complete the next several bars of music that felt to me, 'inevitably' were to follow. 91

I think the quick tempo and 5/4 time signature I decided upon lend themselves well to this sporadic 'on the fly' style of composition, and certainly generate a strong sense of momentum with the irregularity of 5/4 constantly demanding a kind of metric resolution that never arrives (at least not for a while). This approach is by nature, a very chronological way of composing and making progress in sporadic bursts spurred from the last point of progress isn't exactly the ideal method for developing a sound structure or macro-level vision of the piece as a whole. However because this manner of composing shares so much in common with improvisation I believe much of the material has a spontaneous, improvisatorial quality to it, all adding to the desired 'Illusion of Liveness' in the instruments' performances.

\section{Creating liveness in VST percussion}

The bulk of Garden of Earthly Delights can be boiled down to a one bar ostinato rhythm that permeates much of the piece and is (fig.5) performed by bongos and congas (fig.5). In the earliest stages of composing the work I simply looped this

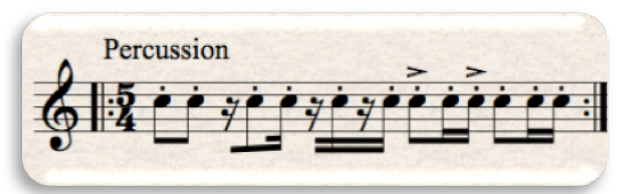
rhythm to create 16 or so bars in order to serve as a basic skeleton of a piece I could respond to and add upon with other instruments. This quick move works fine as a temporary fix for building up a bit of musical length to work with, however once I had secured an introduction to the piece the task then became addressing the painfully noticeable fact that the percussion was precisely repetitive; by default the rhythm is

\footnotetext{
${ }^{91}$ Interestingly enough, in this manner of composing 'in the moment' or 'on the fly', I have come to realize my brain actually functions in much the same way it does when improvising with a guitar in jazz or blues ensemble. I hear what the other players are doing and respond automatically, essentially without conscious thought, with the first musical idea that springs to mind as if it were an inevitability. For more in depth discussion on the concept of composition as improvisation see Derek Bailey, Improvisation: Its Nature and Practice in Music, Da Capo Press, 1993.
} 
quantized and requires adjusting to give a more human character. ${ }^{92}$ This process is called 'humanization'.93

By default MIDI notes will align exactly to a sixteenth-note grid (or other set division), which inevitably results in a metrical and often inhuman effect. Had I been preparing this piece in a hip-hop, dance or other popular genre where both metrical precision and looping of bars are often key traits of the styles, further action may not have been needed, as these are characteristic of those non-live genres. However, my task here is to feign human performance and the fundamental aspect of such is human imperfection (as much as performers strive for otherwise). The action required to breathe life into the instrument essentially involves the 'roughening' of the performance by creating subtle variations in both the position of notes and their velocities.

(fig.6)

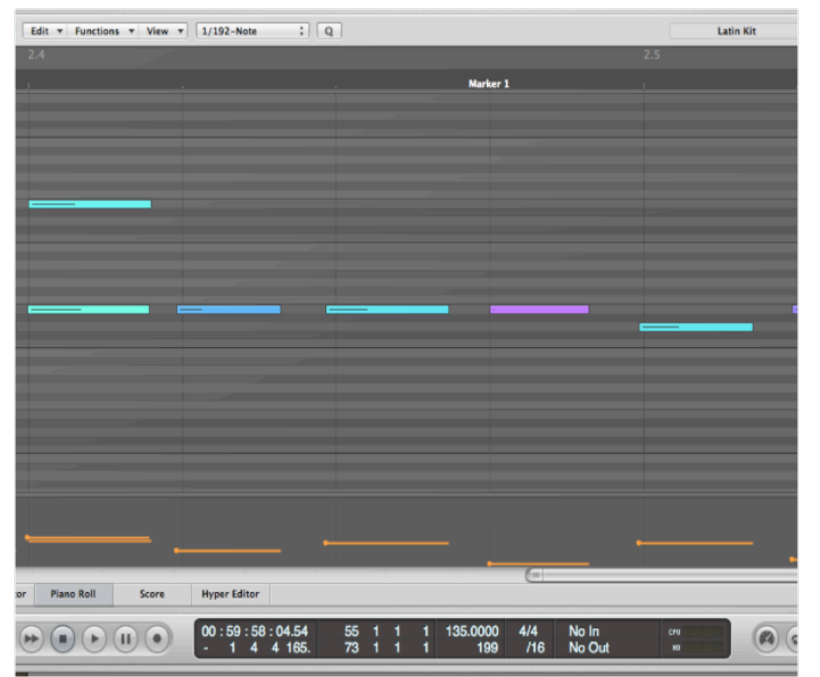

The adjacent screen shot shows the DAW's piano-roll with the notated extract of the bongo rhythm input into Logic's MIDI sequencer (fig.6). The faint vertical lines represent the exact sixteenth-note division and as you can see, the notes do not align with this grid but fall slightly to either side. The velocities of each note (indicated by colour and the drawbars below) also differ from one another. These two processes are then applied to every successive bar in the bongo line and when played back at full tempo, this continuous variation of dynamics and tightness create an aural effect of momentum, 'groove' and 'humanness'. It is hoped that at this point the former sterile and metronomic line begins to create the illusion of liveness of a real percussionist playing.

\section{Cinematic narration}

The track Garden of Earthly Delights comprises two contrasting sections or episodes. The first is jagged, menacing, unpredictable, and with an almost delirious quality to it. The second strives is an expansive, psychedelic and glorious arrival. In achieving these desired sonic qualities, compositional decisions made in the role of a cinematic-narrator pertained to both musical and hyper-musical aspects of composition and production.

To illustrate, the first 'episode' (0:00 - 2:33), with its jagged and ominous quality, decisions pertaining to instrument selection were of prime importance. Heavy use of

\footnotetext{
${ }^{92}$ Refer to CD track 10 for an early version of Garden of Earthly Delights, which is not yet humanized.

${ }^{93}$ More information on humanization techniques can be found in Logic 9's user manual. documentation.apple.com/en/logicpro/usermanual/ Accessed February 2013.
} 
percussion along with percussive articulations from other non-percussion instruments was exploited to help give a spiked and angular characteristic to the sonic stage. Upon the entry of female vocals at $(0: 4 I)$ the first truly 'human' character is introduced into the sonic stage.

In working with the vocalist, I wished to have the effect of a vivacious and slightly delirious sounding female to complement the tone of the first episode. After some experimentation, we found that hybrid of spoken and sung delivery not unlike the sprechstimme of Pierrot Lunaire was most effective in creating this delirious effect.

At the arrival of the second 'episode' at 2:34 there is a sudden and striking shift in all aspects of texture, harmony, time signature and timbre as the piece launches into a kind of psychedelic rock-chorale with a very pronounced $6 / 8$ meter.

In personally evaluating the overall perceived success of liveness in Garden of Earthly Delights, I think the elements of drums and percussion VST instruments have produced successful results. The techniques of humanization worked to good effect and give a sound 'human' backbone to the piece.

Where I am less convinced of liveness is in the second 'episode' where the choir, although stylized, could perhaps be made more cohesive with the previous material. I used the soprano singer over the VST choir as I desired a more pop or gospel quality than a classical one - a style she was capable of performing. However, the sound produced is perhaps too 'glossy' - a result of multi-tracking the same voice - and this choir section could have perhaps benefited from the variation in vocal tone that a real choir, or perhaps even the VST instrument, is capable of. 


\section{II) Chorale \\ CD Track 7 |4:29|}

VST Instruments

Passion Flute ${ }^{\odot}$

Percussion

Bass Guitar

Strings (Pizzicato articulations only)

Requiem Choir ${ }^{\odot}$

French Horns

Celeste

Harmonica

\section{Real}

Guitar

Strings (Arco runs only)

[4 Violins, 2 Violas \& 2 Cellos]

Chorale brings together a mixed choir with elements of orchestral and rock instrumentation. Stylistically, this work aimed to be a kind of inspired synthesis of some of the choral works by Ravel and Boulanger, but with an Ennio Morricone-like cinematic rawness as exemplified by the featuring electric guitar atop a choral texture.

\section{Compositional Process}

It was a combination of improvisation at the piano and in the DAW that lead to the creation of this piece. I find it convenient to be able to voice out chords at the piano in order to compose and hear harmonies at your fingertips, however when hearing back the sound of an actual choir, as is possible using the Requiem Choir $\odot$ VST in the DAW, I found that more adventurous and dissonant harmonies come to life and sound better than they otherwise sound at the piano. ${ }^{94}$ For me this was a rather significant discovery and much of the resulting harmonies heard in Chorale were indeed discovered through experimentation in the DAW.

\section{Creating liveness in the VST Choir}

Chorale is the piece most far removed from live musicianship and features only string runs and a guitar melody as real recorded performances. Everything else heard comprises VST instruments. The reasons for this are purely experimental: I wished to trial working with one of, if not the most difficult-to-emulate instrument, the human voice.

\footnotetext{
${ }^{94}$ Although there is no space to discuss it here, the idea of timbral qualities of differing instruments leading to differing compositional results could prove another interesting topic for discussion.
} 
By far the biggest and most obvious difficulty was making a VST instrument sound like a human choir, and not the tacky third-rate choir sound found on many a programmable keyboards. For this piece I used the VST Requiem Choir $\odot$ and a great deal of attention to the VST's performance parameters were required to in striving to give a convincing performance.

(fig.7)

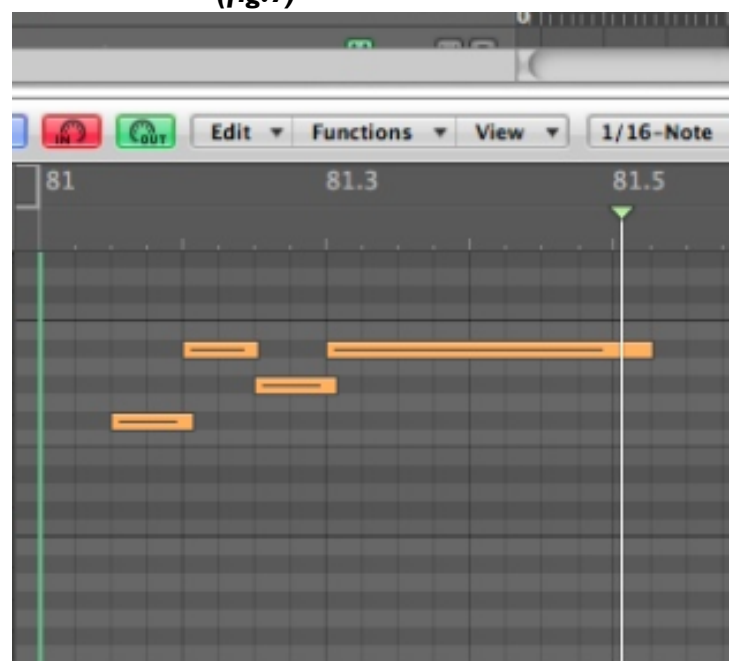

The opening $(0: 00-1: 15)$ strives to create a serene, ethereal quality with the mixed choir sitting below a soprano voice singing Latin text (the default text of the VST) and performing long, drawn out and legato phrases that have a rich harmonic texture. In achieving this quality I had to ensure that the soprano's input notes ever so slightly overlap (fig.7) in conjunction with setting the VST's 'release' parameters to allow for a slight bleeding between the notes (i.e. the

two notes sound simultaneously for a fraction of a second, creating the effect of legato.) The manual manipulating of dynamics were needed for each track of solo voice and choir in attempt to recreate natural swells as heard in a live choral ensemble.

\section{Cinematic Narration}

The desired sonic effect of the work was something larger-than-life, epic or cinematic: a coupling of choral music and rock presented in a hyper-musical form in the sonic stage. Much like cinematic narration that uses aesthetically pleasing visual elements in its cinematography such as sweeping landscape shots with glossy colour grading to depict perhaps a beautiful but foreign setting in an opening shot, Chorale's first introductory episode (0:00 - 2:07) sought to achieve a serene and ethereal quality and this was first generated by use of choir, flute and solo voices.

Opening from an inaudible volume, I wished to fill out the spectrum of the sonic stage in a hyper-musical way. By placing the mixed choir in mid-far proximity and having soprano and tenor voices singing counter melodies at equivalently soft dynamics, but as if at an intimate proximity, this created the aural image of the listener in an enveloping surreal and ethereal choral ensemble.

Following a second sub-episode, heralded by percussion and a harmonic cadence (I:II), the piece's main melodic moment comes with the arrival of guitar at 2:07. The desired effect was to be ethereal and uplifting, yet earthy. This was achieved with the decision to juxtapose gritty, overdriven electric guitar with a serene choir producing rich 
and extended harmonic textures. Again multiple proximities were used in the mix with guitar heard right at the forefront of the sonic stage and the choir in the background. Bass guitar is also added to fill out the lower register.

In a contrapuntal style, and again, contrasting the gritty with the serene, I used harmonica (2:20) and flute (2:30) performing counter-melodic material against the guitar line. This introduction of new instruments announces the 'colour crescendo' used in acoustic orchestration, and from 2:30 the choral chords are double by background tremolo strings before being joined by real (recorded) string runs, timpani and rolled cymbal, all of which crescendo towards a climax marked by a bass drum and tam-tam hit at 2:44.

From 2:56 until the ending the musical material serves as an extended coda with flute and soprano voice sharing the focus and placed in close proximity against a backdrop of tremolo strings and celeste playing a cyclical chordal pattern before a dissonant choral $\operatorname{climax}(3: 29$ - 4:29).

In evaluating the results of the perceived realism of instruments heard in Chorale I think the VST choir, although true sounding as far as timbre is concerned, lets down the piece in that it does exhibit some quite unnatural sounding phrasing. I think there is much to be improved upon with regard to imitating the fluidity innate in a human performance and the lack of convincing legato ultimately lead to the disruption of the illusion of liveness. Although much attention was given to the attempt to create legato, perhaps more understanding of the subtleties of this VST was required. 


\section{III) Dizzy Night \\ CD Track 8 |3:49|}

VST Instruments

Passion Flute ${ }^{\odot}$

Percussion

Drums

Fender ${ }^{\circledR}$ Scarbee (P Bass) Bass Guitar

Strings (Pizzicato articulations only)

Requiem Choir ${ }^{\odot}$

Hammond Organ

Piano

French Horn
Real

Voice

Strings (Arco runs only):

[4 Violins, 2 Violas \& 2 Cellos]

Guitar

Dizzy Night is a fast tempo, latin flavoured composition showcasing a vast array of percussion instruments and featuring flute, female voice and guitar in prominent solo roles. With regard to narrative, the piece endeavors to take sustain a sense of propulsion forward, sustaining momentum throughout and giving the listener a sonic ride through use of a multitude of instrumental colours.

\section{Compositional Process}

The melodic and harmonic material heard in the verses of this piece were loose ideas I had prior to this project, while the opening, interludes and embellishments to the verses were composed much in the same semi-improvisatory way Garden of Earthly Delights was: within the DAW environment, hearing progress through playback and responding in an improvisatory manner. The tempo and heavy use of percussion are also elements similar to Garden of Earthly Delights, however, this pan-latin style of rhythm required yet even more attention to the humanizing of the percussion. 


\section{Creating liveness in the VST Flute}

The Passion Flute ${ }^{\odot}$ VST features predominantly in this piece. As with the techniques applied to the use of Requiem Choir ${ }^{\odot}$ in Chorale, much effort was made to create the feel of legato, so the careful and subtle overlapping of inputted notes was a significant part of realising a convincing instrumental performance simulation using the VST.

As well as using regular single note articulated samples this instrument comes with the capability to perform a multitude of pre-recorded short phrases, which can be glued together to make longer phrases for use in solos. Examples of this can be heard in the fluteguitar 'trade-off' section of the piece (2:55 - 3:16). Although this creates impressive, virtuosic and utterly authentic sounding solos, the issue now is that the composer's 'individual creativity' takes something of a back seat to an arranging role and subsequently brings back the discussion of creative control and autonomy.

Using sampled phrases in one's own work can be thought as the compositional equivalent of a composer asking an instrumentalist to improvise for a number of bars in his or her piece: Melodically or rhythmically it is not the composer's own creation and this can be thought of as a very backward step in terms of compositional autonomy, perhaps even to the point where an argument for plagiarism could be put forth. ${ }^{95}$ Given that a VST's most common use is the devising of melodic or rhythmic material from micro-sampled material, in the form of short articulations from which to create a performance, this would bring about a debate over how small a sample must be before can be regarded as the composer's own. Regardless of inherent 'originality' in the sampled materials, I believe the gritty assortment of flutter tonguing, over-blowing and scalar runs created the impression of an ultimately human sounding performance.

\section{Cinematic Narration}

The overall desired sonic effect in this piece was a fast paced ride through a latin inspired sound-world with a kaleidoscope of colours popping into the forefront and moving back out of aural focus to create a pseudo-polyphonic effect.

I wished to begin the piece as aggressively as possible and establish a mood that was colourful, wild and chaotic. The opening gesture comprises a timpani role heralding blitzing strings run before a heavily pronounced downbeat while percussion and organ sustain an

\footnotetext{
${ }^{95}$ Though Passion Flute ${ }^{\odot}$ and virtually all other VST instrument and loops are specifically sold and designed for both recreational and commercial and therefore, are royalty free, an intellectual property issue arises nonetheless. Examples of hit pop songs derived from VST loops in recent years include: Rihanna's Umbrella which uses a stock loop from Apple ${ }^{\odot}$ computer's entry level DAW Garageband ${ }^{\odot}$ named Vintage Funk Kit 03, as well as Usher's Love in the Club which uses loops Euro Hero Synth (01 and 02) similarly from a Garageband ${ }^{\odot}$ expansion pack named Remix Tools Jam Pack (2007).
} 
aggressive sounding major chord under wild and animalistic flute flutter-tonguings. These gestures were decided upon in order introduce the listener to most of the instrumental 'characters' that would appear within the narrative arc of the piece.

The lengthy instrumental introduction (0:00 - 1:00) showcases the multitude of instrumental colours used in the piece with the intent of creating a kaleidoscopic visual image that fills the sonic stage. A large part of achieving this effect required that an elaborate array of percussion be used. Three percussion VST instruments were used to bring about this level of colour, including a latin, orchestral, and rock kit, each with a specific rhythmic and colouristic function.

High-pitched percussion such as wood blocks and castanets were assigned to the latin kit, mid range percussion of snare and toms were given to the rock kit, while deep register accents, such as orchestral bass drum hits and timpani rolls, were given to the orchestral kit. This percussion section alone fills the sound spectrum of the sonic stage but with the addition of abrupt and jagged piano, guitar and flute entries atop the percussion's interlocking rhythms, momentum and colour, a kaleidoscopic effect was achieved.

In an extra-musical, compositional narrative gesture, I wished to create the effect of the singer's unvoiced thoughts being represented in the flute, while she sings to create a kind of musically depicted contrapuntal conflict in her mind. As she sings the ascending scale to the text 'two bodies entangled...'( $(I: 3 \mathrm{I})$, the flute echoes this with a counter melody to the effect of both expressing this inner voice and extra-musically highlighting the word 'entangled' in this melodically entangled gesture. 


\section{IV) Vibrations \\ CD track $9|4: 25|$}

VST Instruments

Passion Flute ${ }^{\odot}$

Percussion

Drums

Strings (Pizzicato articulations only)

Hammond Organ

Celeste

Harmonica

\section{Real}

Voice

Guitar

Bass Guitar

Strings

[4 Violins, 2 Violas \& 2 Cellos]

Vibrations is the simplest of the four tracks in the suite. In essence it is an orchestrated poprock track that blends a standard rock ensemble of guitar, bass, keyboard and drums with a string section, all within a 1970s Motown and jazz harmonic sensibility.

\section{Compositional Process}

The final track of the suite began life as a more conventional pop-rock song I wrote for a band I played in several years ago. I believed it might lend itself to having added instrumental colours and would make a good exercise in orchestration taking a similar approach to that of Psathas' work with Little Bushman. As the most simple and 'pop-like' piece in this suite, sonically the work seeks to depict a rock band performing in an idealized live context with a chamber sized string orchestra, and shares the instrumentation found in many Motown recordings.

Drums, bass, guitar and keyboards provide the bones of the piece (as previously written for the band I played in) and newly composed material added for this project was largely extra percussion along with melodic content in the strings, flute and celeste. Real-time playback from the DAW aided in composing cantabile-style counter melodies by way of allowing me to improvise overtop of the live playback until a suitable melody was devised. This can also be credited to the improvisatorial approach used in Garden of Earthly Delights where I could simply listen and respond back by way of improvising just using my own voice to find suitable sounding counter-melodic material. 


\section{Cinematic Narration}

Much like Tuna in the Brine, three distinct sonic strata can be identified, in the form of an orchestral layer of strings and percussion, a rock-ensemble comprising guitar, drums and bass, and a female vocalist. Tying together these in a cohesive way within the sonic stage was the role of the cinematic narrator.

The strings are given a hyper-musical scope in that they move between foreground and background proximity within the sonic stage, shifting between functioning as a background drone, the focal point of the song as the melody instrument, and sounding right in your eardrum.

This piece's textual material is about sound and the even more abstract concept of becoming one with sound. In the introduction to this work I wished to create the narrative but abstract image of the birth of sound; starting from an inaudible whisper and progressing into an almighty roar.

In striving for this narrative effect, the piece opens with low, almost inaudible arco strings in unison. The strings, though pianissimo, are placed right at the forefront of the sonic stage to the effect of whispering right into the listener's ear. Slowly a contrary motion effect emerges as the string octet begins an eerie upwards glissando while a VST double bass slides downwards. The strings become more agitated, now beginning a tremolo and still sliding upwards beyond the fingerboard to the effect of a complete filling of the sonic-stage in an atonal, clustered and suspense-ridden wall of sound that feels as if it is about to burst. To achieve this effect, in the rehearsing and recording stage I had to urge the players to perform as grotesquely as possible; something which went against their intuition. Many takes of this introduction were needed before a suitably 'grotesque' performance was captured, and I continually had to spur them after each take to try it once more with more "anger, intensity and horror".

This build reaches a climax and gives way to a sudden entry of percussion, bass, and a string run in the minor mode; a contrasting point of harmonic arrival to the previous sound-cluster. It is following this, that the strings drop to an accompanying drone role giving way to metrically pronounced rock beat comprised by percussive guitar rhythms, drum rimshots and eventually a steady bass line. After establishing a groove in a minor key for a number of bars the piece breaks down again, reiterating the introductory strings glissandi then launches into an entirely new harmonic terrain; the predominant material of the song. (I:2I - 3:25).

As in Chorale, it is in this section that the same concept of juxtaposing contrasting timbral textures is applied to the effect of having the grit of drums, bass and percussion 
heard against to the more ethereal celeste, organ and female vocals doubled by the string line. These contrasting sonic strata, differing in timbre and proximity, yet harmonically compatible, allow Vibrations to generate a sense of depth that would otherwise be impossible in a live acoustic environment. 


\section{V \\ Conclusions}

This project is but the tip of the iceberg of a far greater and multifaceted discussion of the ways we think about, listen to, and create music in the modern, mediatized world. I chose this project, as I believe the issues addressed in it are ones that are very pressing and relevant to the modern composer and to the future of composition. Many of the skills learned through the completion of this project will determine the manner in which I approach composition for the rest of my life.

I also wished to explore the means of talking about and understanding this new hybrid role of producer-composer and the relevance of the tools associated with it, about which there is no general consensus. It is clear that the technology driven merging of the roles of composer and producer has brought about a wholly new role possessing a creative control over recorded music's sonic stage to a degree comparable to that of the conceptual cinematic narrator of film theory. Such an extension of creative control also suggests a move towards creative autonomy and independence from other musician's input, and was itself an initial motivation for the composition of my suite. I believe it true that in my works I was able to achieve a degree of creative control that would be impossible without the aid of the technology used. However, the fact remains, no matter how much a producer-composer strives for creative autonomy there will always be an inextricable link to the musician or technician involved in the creation of that technology.

I can understand the disdain for a technology that might warp one's expectations and understanding of orchestration and performance, but I believe with a solid educational grounding, the tools' benefits far outweigh any harm they might do to the budding composer. I am convinced that hearing real-time instrument simulations when composing, and the skill of creating convincing instrumental performance simulation for presentational or rehearsal purposes, present real benefits to creativity and pedagogy alike.

Having access to VST technology as a producer-composer of recorded music presents virtually no limitations with regard to the instrumentation he or she wishes to write for. This is a very significant paradigm shift from the acoustic instrumental/vocal culture of commissioning a work whereby, an ensemble (where the instruments are predetermined) approaches the composer who ultimately has no say in the matter of instrumentation. I can reference a personal example of this is a recent commission I have been given with the New Zealand National Youth Orchestra. 
Unless one happens to have a considerable amount of disposable income or eighty exceptionally generous professional musician friends, some form of commission or prize is the only way a composer will ever see his or her work performed by a professional orchestra. In my case however, due to programming with other pieces in the forthcoming concerts (August 30th and 31st, 2013 in Michael Fowler Centre Wellington, and the Town Hall, Auckland), the ensemble I am to write for will not contain a harp and only two percussionists (not the standard four). Despite the fact I would prefer more percussionists, budgetary limitations do not allow for it and I have no say in the matter so must write for what is available. Obviously any commission, regardless of the ensemble, is always a fantastic opportunity and not something the budding composer has the right to dispute.

Production as composition, however, presents a creative situation in which there are essentially no limitations placed on the composer in terms of the forces he or she may wish to write for. I this, I do see real potential benefits for composers of limited means to be able to realize in full their projects, no matter how ambitious these are.

Though technological innovation is inevitable and technologies such as the DAW and VST are most definitely here to stay, I am all too well aware of the contention and backlash arising from floating the idea of virtual instruments replacing human musicians in recordings. I am convinced that this is not the case and that the use of such technologies are merely an extra set of tools in the composer's toolkit that will happily co-exist along side musicians perhaps even to the advantage of everyone.

I believe my suite serves as an example of production with predominantly VST instruments, which achieves some degree of success in realism, and which with time could be improved upon as my production skills develop. However I can never envisage myself achieving entirely convincing realism when producing with solely VST technology as a replacement for live musicians. Presently I believe use of VST technology and the techniques used to bring about realism, at their highest aspiration, should be used in creating high quality simulations of real instrumental ensembles that are useful in many pedagogical and practical scenarios requiring a clear sharing of musical ideas. However with regard to use in recorded music considered to be in its final form (be it art, commercial, film or other music) I believe VSTs should remain only supplementary to, or be used in conjunction with, live musicians for the best results. Time will tell what the standard practise will be in the future. 


\section{Bibliography:}

\section{Literature}

Auslander, Philip. Liveness. London: Routledge, 1999.

Bailey, Derek. Improvisation: Its Nature and Practice in Music, Da Capo Press, 1993.

Baudrillard Jean. Simulacra and Simulation. University of Michigan Press, 1995.

Bell, Elizabeth S. Theories of Performance. Los Angeles: Sage, 2008.

Brown, Royal S. Music andlas Cine-narrative or: Ceci n'est pas un leitmotif. From A Companion to Narrative Theory. Oxford, UK: Blackwell, 2005.

Burgoyne, Robert. The Cinematic Narrator: The Logic and Pragmatics of Impersonal Narration. Journal of Film and Video: Spring 1990.

Burnham, Scott. Beethoven Hero. New Jersey: Princeton University Press, 1995.

Cobley, Paul. Narrative. New York: Routledge, 2001.

Doyle, Peter. 'From 'My Blue Heaven' to 'Race with the Devil: Echo, Reverb and (Dis)ordered Space in Early Popular Music Recording'. Popular Music. Vol. 23, no. I. Cambridge University Press, 2004, pp. 31 -49.

Eno, Brian. 'Pro Session: The Studio as Compositional Tool', Down Beat 50, 1983. pp. 65-67.

Frith, Simon. Performing Rites: On the value of popular music. Cambridge: Harvard University Press, 1996.

Geddes, Chris. The Digital Revolution: The role of the Digital Audio Workstation in the cultural shift from analogue to digital audio. University of Otago Press, 2011.

Gould, Glenn. 'The Prospects of Recording'. High Fidelity. Vol. 16, no. 4, April 1966 pp. 4663. 
Hambling, Robert. Across the Night - The Creation of Diorama. New South Wales, Australia: Atlantic/WEA, 2002.

Johnson, Derek and Poyser, Debbie. 'Steinberg Cubase VST: Audio Sequencer'. Sound on Sound, July 1996.

Julien, Olivier. 'The Diverting of Musical Technology by Rock Musicians: The Example of Double Tracking'. Popular Music. Vol. 18, no.I. Cambridge University Press, 1999.

Katz, Mark. Capturing Sound: How Technology Has Changed Music. University of California Press, 2004.

Moorefield, Virgil. Producer as Composer. Cambridge, Massachusetts: MIT, 2010.

Peaslee, Mike \& Folmann, Troels. Tonehammer: Requiem Light (User Manual), Tonehammer 2010, www.8dio.com.

Sanden, Paul. Liveness in Modern Music: Musicians, Technology, and the Perception of Performance. New York: Routledge. 2013.

Thompson-Jones, Katherine. The Literary Origins of the Cinematic Narrator. Oxford. Journal of Aesthetics, Vol. 47, No. I, January 2007.

Winer, Ethan. 'Add Realism to Your Synthesized Sequences'. Recording Magazine, November 1997.

Zak, Albin. The Poetics of Rock: Cutting Tracks, Making Records, University of California Press 1997.

\section{Interviews}

Gibson, Mike. Interview at Munki Studios, 24th November, 2013.

Neil, John. Interview at Park Road Post (Film Post-Production Facility), I5 October 2013.

Prebble, Lee. Interview at Surgery Studio, 23 May 2013. 


\section{Recordings}

Les Paul and Mary Ford, 'How High The Moon', Capitol, 1951.

Little Bushman, 'Karanga', on Little Bushman: Live in concert with the NZSO, (- Little Bushman, 2010.

Silverchair, 'Tuna in the Brine', on Diorama. Atlantic, 2002. 


\section{Glossary of Terms}

Cinematic Narration: In film, the sum of the technical aspects such as lighting, cinematography and mise en scène which all describe the physical 'realities', laws and boundaries governing the fictional world created. In this exegesis I argue that the producercomposer's role is the musical equivalent of the Cinematic Narrator dealing in harmony, timbre, rhythm and tempo, and more technical and aesthetic elements of reverb, compression, mixing and mastering in order to illustrate and 'narrate' the intended 'fictional' sonic world.

DAW: Digital Audio Workstation. An integrated recording, editing, mixing and mastering application.

Humanisation: The process of editing MIDI input notes in a DAW in a way that mimics human performance. This includes the manual or algorithmic deviating of note velocities and rhythmic placement to mimic human imperfection.

Instrumental Performance Simulation: The craft of fabricating human sounding performances from VST instruments.

MIDI: Musical Instrument Digital Interface.

Quantisation: The process of making MIDI input notes conform to a fixed set of discrete rhythmic values, often for a rhythmically metronomic effect.

Sonic Stage: The stereo-field of audio: the domain in which sounds occupy and move through a perceived 'space' in a recording.

Sonic Strata: Observably distinct layers of sound in a recording.

VST Instrument: Virtual Studio Instrument. A virtual means of utilizing a library of recorded articulations of an instrument, usually comprising that instrument's full range chromatically, and accessible for performance via a MIDI keyboard, and subsequently recorded or 'input' into a DAW for editing. 